\title{
Thymoquinone Improved Nonylphenol-Induced Memory Deficit and Neurotoxicity Trough its Antioxidant and Neuroprotective Effects
}

\section{Mandana Lotfi}

Student Research Committee

\section{Sohrab Kazemi}

Cellular and Molecular Biology Research Institute

\section{Anahita Ebrahimpour}

Cellular and Molecular Biology Research Institute

\section{Fereshteh Pourabdolhossein}

Cellular and Molecular Biology Research Institute

\section{Seyed Leila Satarian}

Department of Stem Cell and Developmental Biology

\section{Atiyeh Eghbali}

Department of Stem Cell and Developmental Biology

Ali Akbar Moghadamnia ( $\sim$ aliamoghadamnia@gmail.com )

Cellular and Molecular Biology Research Institute https://orcid.org/0000-0003-0100-978X

\section{Research Article}

Keywords: Nonylphenol, Thymoquinone, Neurotoxicity, Astrocyte

Posted Date: September 23rd, 2021

DOl: https://doi.org/10.21203/rs.3.rs-920975/v1

License: (c) (i) This work is licensed under a Creative Commons Attribution 4.0 International License. Read Full License 


\section{Abstract}

Nonylphenol (NP) as a well-known endocrine-disrupter chemical (EDCs), has several harmful effects on the CNS such as neuroendocrine disruption, cognitive impairment, and neurotoxicity. Thymoquinone (TQ) is a main bioactive compound in the black seeds of nigella sativa (NS) possesses antioxidant, antiinflammatory, and neuroprotective properties. This study was designed to assess the neuroprotective effect of TQ against NP-induced memory deficit and neurotoxicity in rats. To induce memory impairment, NP $(25 \mathrm{mg} / \mathrm{kg})$ was used as gavage in male Wistar rats for 21 days. TQ i.p. injection at doses 2.5, 5, and $10 \mathrm{mg} / \mathrm{kg}$ was done in NP-treated animals at the same time. Morris Water Maze (MWM) test was performed to assess spatial memory. The rats ' hippocampus tissues were isolated for histopathological testes. Biochemical, molecular and cellular tests were done for proving more details. The results showed TQ at dose $5 \mathrm{mg} / \mathrm{kg}$ significantly improved NP-induced memory impairment. Histological data proved that TQ decreased the number of necrotic cells in the hippocampus which was increased in NP-treated animals. Biochemical analysis showed that the levels of glutathione (GSH) and total antioxidant capacity (TAC) were significantly increased in TQ treated groups compared to the NP group. The molecular analysis has shown that NP increased GFAP and decreased a-Syn expression level and TQ treatment did the reverse. In vitro study in astrocytes isolated from mice brain proved that TQ significantly increased cell viability in cytotoxicity induced by NP. This study strongly indicates that TQ has therapeutic and neuroprotective effects on NP-induced neurotoxicity through reduction of oxidative damages and neuroinflammation.

\section{Introduction}

Nowadays, the potential function of endocrine-disrupting chemicals (EDCs) on general health as a main concern that has been discussed extensively for many years in science and the public[1]. EDCs have toxic effects on endocrine, behavioral, nervous, and cognitive systems[2]. Nonylphenol (NP), as a member of the alkylphenol class, is classified to the EDCs family[3]. NP is commonly used in manufacturing several products such as detergents, cosmetics, emulsifiers, paints, and pesticides[4]. NP toxicity has been reported in different organs, including skin, eyes, respiratory system, brain, thyroid, liver, pancreas, bladder, kidney, breast, and reproductive system[5-8]. Pieces of evidence have shown that NP induces cognitive impairment[9], neurogenesis disruption, and learning and memory deficit[10]. After ingestion, NP circulates through the bloodstream all over the CNS and passes quickly through the blood-brain barrier (BBB) because of its lipophilic structure[11]. NP can cause neurotoxicity through several mechanisms including inflammation[12], oxidative stress[13], gliosis, and neural loss[14]. A previous study has indicated that oral administration of NP at the dose of $25 \mathrm{mg} / \mathrm{kg}$ induced neurotoxicity and learning and memory impairment accompanied by oxidative stress, hippocampal tissue injury, and increased inflammatory and apoptotic-related genes expression[15]. Another study has proved that NP dysregulated the balance of oxidant /antioxidant by reducing the levels of superoxide dismutase (SOD), catalase (CAT), and glutathione (GSH) in the brain[16]. Moreover, it has been reported that exposure to NP stimulated glial cells and increased inflammatory factors in glial cells in the CNS[17]. 
Today, scientists have been attracted to use natural compounds with antioxidant and anti-inflammatory properties as the potential therapeutic target in several neurological diseases[18]. Nigella sativa is a medicinal plant widely used in various diseases treatment, including asthma, headache, bronchitis, infection, high blood pressure, digestive problems, and eczema in Africa and the Middle East[19]. Thymoquinone (TQ), as a main bioactive constituent of the black seed (Nigella sativa), has antiinflammatory[20], antioxidant, anti-neurodegenerative, and anti-tumor properties[21]. TQ in normal conditions acts as a potent antioxidant and reduces the production of superoxide radicals and lipid peroxidation. In parallel, it increases the activity of the antioxidant enzymes such as glutathione reductase (GR), GSH, CAT, and SOD[22]. Several studies have proved that TQ prevents neuronal apoptosis induced by ethanol cytotoxicity in primary neurons and protects PC12 cells against cytotoxic oxidative injury[23]. Moreover, TQ can suppress neuroinflammation in BV2 microglia (MG) and mixed glial cells[24]. A study reported that $T Q$ at doses of 5 and $10 \mathrm{mg} / \mathrm{kg}$ improved learning and memory function on animal Alzheimer's models by its anti-neurodegenerative properties[25]. Another study has demonstrated that TQ at doses of 2.5, $5,10 \mathrm{mg} / \mathrm{kg}$ enhanced lipopolysaccharide (LPS)-induced learning and memory deficit through decreasing inflammatory cytokine levels and oxidative damage[26]. In addition, neuroprotective effect of TQ reduced the ROS level and the Parkinson's disease (PD) symptoms in the rotenone induced animal model of $\mathrm{PD}[27]$.

Although recent studies suggest that antioxidant compounds reduce NP toxicity, there is still no safe and definitive solution to prevent and treat NP neurotoxicity. Thus, this study was designed to assess the neuroprotective effects of TQ on memory impairment and neurotoxicity induced by NP in vitro and in vivo. First, isolation and culture of astrocyte from the mouse brain was performed and then characterized with Glial Fibrillary Acidic Protein (GFAP), Glutamate Aspartate Transporter (GLAST), and calcium-binding protein B (S100- $\beta$ ) antibodies by immunofluorescence technique. Moreover, the MTS test evaluated the effects of different doses of TQ and NP on astrocyte cell viability. Spatial learning and memory function were assessed by MWM task in all treated groups. Furthermore, Histological staining (H\&E and NISSL) was used to evaluate hippocampal injuries. The biochemical assessment measured total antioxidant capacity (TAC), Malondialdehyde (MDA), GSH, and SOD. Finally, GFAP and Alpha-synuclein (a-Syn) genes expression analysis was performed by qPCR.

\section{Materials And Methods}

\section{Chemicals}

Thymoquinone (TQ), Nonylphenol (NP), Dulbecco's Modified Eagle Medium (DMEM), Fetal bovine serum (FBS), Penicillin/Streptomycin, Non-essential amino acid, L-glutamate, Hank's balanced salt solution (HBSS), Poly-L-ornithine (PLO), Diethyl ether, Trypsin, 4\% paraformaldehyde, Triton X-100, PBS, MTS kit, were obtained from Sigma-Aldrich Chemical (USA). Ketamine and Xylazine were purchased from Alfasan (Woerden Co., Netherlands). Primary antibodies GFAP (Sigma-Aldrich, G3893, 1/200), GLAST (Abcam, Ab416, 1/200), S100ß (Abcam, Ab52642, 1/200) were used in our study. 


\section{Cell culture}

\section{Astrocyte isolation and culture}

The astrocyte cell was isolated from neonate mice (wild-type NMRI) aged 5-7 days. The astrocyte cell culture media (DMEM, high glucose $+1 \%$ Penicillin/Streptomycin $+15 \%$ fetal bovine serum $+1 \%$ nonessential amino acid $+1 \%$ I-glutamate), as well as cold HBSS (Hank's balanced salt solution) with $1 \%$ Penicillin/Streptomycin for isolation medium, was prepared before the procedure. Poly-L-ornithine (PLO, $0.001 \%$, Sigma-Aldrich, P4707) was used to coat T25 flasks for one day at $37^{\circ} \mathrm{C}$ in the $\mathrm{CO} 2$ incubator.

Then, mice were euthanized, and their brains were extracted and put on ice in a dish filled with HBSS/ Penicillin/ Streptomycin. The cerebellum and olfactory bulbs were removed and placed into another dish filled with HBSS to remove the meninges of the cortex. Now, in the third dish, the tissues were cut into small pieces by sharp blades. The fragments were then moved to a $50 \mathrm{ml}$ Falcon tube containing HBSS $/ 0.5 \%$ trypsin, combined, and incubated for about 7-10 minutes in a water bath at $37{ }^{\circ} \mathrm{C}$. The suspension was then passed through a $100 \mathrm{M}$ cell strainer after incubation. The pieces of cortex tissue were centrifuged at $1500 \times \mathrm{g}$ for 5 minutes. Then, the supernatant was eliminated, and the tissue was dissociated into a single cell suspension by adding $10 \mathrm{ml}$ of astrocyte media and then intensive pipetting 20-30 times. The cell suspension was then seeded in a T25 culture flask and incubated in a $\mathrm{CO} 2$ incubator at $37^{\circ} \mathrm{C}$. The primary cell culture medium was changed four days after plating and every two days after that. After 7-8 days, MG was extracted by shaking the cells at $240 \mathrm{rpm}$ for 3 hours. After shaking, the culture medium was changed, and the cells were incubated at $37^{\circ} \mathrm{C}$ in the $\mathrm{CO} 2$ incubator. On day 14 , the cells were shaken at $180 \mathrm{rpm}$ overnight to separate oligodendrocytes and were then dissociated using $0.5 \%$ trypsin. FBS was used to inactivate the trypsin, and the cells were centrifuged at $1500 \mathrm{~g}$ for 5 minutes before being seeded on T25 culture flasks[28].

\section{Characterization of astrocytes}

Cell cultures were fixed for 15-20 minutes with $4 \%$ paraformaldehyde (Sigma-Aldrich, P6148) and permeabilized or 30 minutes at room temperature (RT) with $0.5 \%$ Triton X-100 (Sigma-Aldrich, T8532) in PBS. The cells were incubated with primary antibodies in blocking solution overnight at $4{ }^{\circ} \mathrm{C}$, and then secondary antibodies (1:1000; Invitrogen) were applied for $1 \mathrm{~h}$ in RT. Then to visualize the nuclei, cells were stained for 5 minutes with 49, 69-diamidino-2-phenylindole (DAPI, Sigma-Aldrich, D-8617) and observed under Olympus IX71 microscope (Table 1).

\section{Assessment of the astrocyte viability by MTS}

MTS assay (Promega, G5421) was used to study the effects of different doses of NP, TQ and combination of NP and TQ on cell viability as previously described[29]. Astrocytes were cultured in a 96well culture plate at a density of $1 \times 10^{4}$ cells per well. After being cultured for 24 hours, the cells were treated for another 24 hours with different concentrations of NP $(0.25,0.5,1,10,20,40,80,100 \mu \mathrm{M})$, TQ $(2.5,5,7.5,10,12.5,15,17.5,20 \mu \mathrm{M})$ and combination of NP $(40,80 \mu \mathrm{M})$ and TQ $(2.5,5,7.5,10 \mu \mathrm{M})$. At 
the end of treatment, $20 \mu \mathrm{l}$ of MTS solution was added to each well, and the plates were incubated at $37^{\circ} \mathrm{C}$ for 3 hours. On the microplate reader, the absorbance values of each well were then determined at $490 \mathrm{~nm}$.

\section{In vivo experiments}

\section{Animals}

Male Adult Wistar rats (150-200 g) were obtained from central animal house, Babol University of medical science, Babol, Iran. All animals were cared for under standard conditions (temperature $\left(22 \pm 2{ }^{\circ} \mathrm{C}\right)$, humidity (60\%), and a $12 \mathrm{~h}$ light/dark cycle), and food and water were freely accessed. All experimental protocols were according to the international guidelines for care and use of laboratory animals and approved by the ethical committee of Babol university committee (IR.MUBABOL.REC.1398.026).

\section{Experimental Design}

Rats were randomly divided into six groups and the treatment duration for NP and TQ was 21 days: (1) Control (CRL+Soy Oil): Soy oil as an NP and TQ vehicle was administrated orally from the first day of study till day 21. (2) NP: rats were received $25 \mathrm{mg} / \mathrm{kg}$ of NP by gavage, (3) NP+TQ $(2.5 \mathrm{mg} / \mathrm{kg})$ : rats were i.p injected $2.5 \mathrm{mg} / \mathrm{kg}$ of TQ after gavage of NP $(25 \mathrm{mg} / \mathrm{kg})$, (4) NP+TQ $(5 \mathrm{mg} / \mathrm{kg})$ : rats were i.p injected $5 \mathrm{mg} / \mathrm{kg}$ of TQ after gavage of NP $(25 \mathrm{mg} / \mathrm{kg})$, (5) NP+TQ $(10 \mathrm{mg} / \mathrm{kg})$ : rats were i.p injected $10 \mathrm{mg} / \mathrm{kg}$ of TQ after gavage of NP $(25 \mathrm{mg} / \mathrm{kg}),(6) \mathrm{TQ}(10 \mathrm{mg} / \mathrm{kg})$ : rats were the only i.p injected $10 \mathrm{mg} / \mathrm{kg}$ of TQ. The doses of NP (25mg/kg)[15], and TQ $(2.5,5,10 \mathrm{mg} / \mathrm{kg})$ [30] were selected based on previous studies. NP and TQ were freshly prepared by dissolving NP and TQ in soy oil in volume $0.5 \mathrm{ml}$. At the end of the 21 days, the MWM behavioral test evaluated learning and memory function. At the end of the study, the rats were fully anesthetized with ketamine/xylazine, and half of the rat population in each group was perfused for histopathological study. Brain tissue of the other half was stored in the freezer- $80^{\circ} \mathrm{C}$ for biochemical and molecular study.

\section{Morris Water Maze (MWM)}

MWM is commonly used as an accurate behavioral test to assess rodent spatial learning functions[31]. The MWM test was performed to determine the effect of TQ treatment on spatial learning and memory impairment at the end of the 21 days. All experimental trials were done at the same time of the afternoon. Shortly, animals were kept in the MWM test environment for $24 \mathrm{~h}$ before the experiments for adaptation and then were trained four trials (times) a day for four consecutive days. There were at least five-minute intervals between two successive trials. The animal was allowed to find a hidden platform (Q4) in 60 secs. The swimming escape latency (time spent to find the hidden platform) parameter was analyzed to evaluate the spatial learning. Swimming velocity was used to evaluate the motor activity of the animals in the behavioral experiment. To evaluate the spatial memory on probe trial (day 5), Each rat was let to swim for 60 secs in the maze without the platform. We used the duration in the target zone (Q4) to 
assess spatial memory function in all experimental groups. To record and analysis MWM data, Noldus Ethovision XT (11) software (Netherlands) was used.

\section{Sample Preparation}

To prepare serum, the first $1 \mathrm{ml}$ of blood was collected from each animal without anticoagulants. Then, it was allowed to stay at $25^{\circ} \mathrm{C}$ for 10 minutes. Blood samples were centrifuged at $3000 x$ for 10 min, and the serum was separated.

To prepare supernatant from brain tissue, $2.7 \mathrm{ml}$ of $150 \mathrm{mM} \mathrm{KC1}$ was added into $300 \mathrm{mg}$ of wet tissue in a $2 \mathrm{ml}$ centrifuge tube. Then, homogenized on ice using a Teflon-Potter-Elvehjem glass or homogenizer and centrifuged at $1600 \mathrm{~g}$ of for 10 minutes at $4{ }^{\circ} \mathrm{C}$. The supernatant was separated and was used in biochemical assays.

\section{Biochemical Assay}

To measure biochemical parameters, serum and brain supernatant were used. The levels of malondialdehyde (MDA), SOD, TAC, and GSH were measured according to the manufacturer's instructions of an MDA, SOD, and TAC test kits (Teb Pazhouhan Razi, Iran) and GSH reaction kit (Navand Salamat, Urmia, Iran). Briefly, MDA is measured during a colorimetric reaction with thiobarbituric acid in an acidic solution at a temperature of $90-100^{\circ} \mathrm{C}$ and read at a wavelength of $535 \mathrm{~nm}$. SOD kit catalyzes the free anion radical of superoxide into oxygen and peroxide molecules by producing a chromogen and assessed at a wavelength of $420 \mathrm{~nm}$ by spectrophotometer. TAC assay kit is based on the reduction of $\mathrm{Fe} 3+$ to $\mathrm{Fe} 2+$ due to antioxidants action and read at a wavelength of $412 \mathrm{~nm}$ by spectrophotometer. GSH acts as an antioxidant by protecting cells from free radical damage. GSH was measured based on the GSH recycling system by DTNB and glutathione reductase and samples read at the wavelength $412 \mathrm{~nm}$ by spectrophotometer. All biochemical experiments were done in conformity with their kit instructions and were repeated in three independent experiments.

\section{Histological Analysis}

\section{Nissl Staining}

Animals were anesthetized and then perfused with phosphate buffer solution (PBS $0.1 \mathrm{M}$ ) followed by $4 \%$ paraformaldehyde in 0.1 M PBS ( $\mathrm{pH} 7.4$ ). Brains were removed and post-fixed in PFA $4 \%$ at $4^{\circ} \mathrm{C}$ overnight. Then, tissues were dehydrated in a different alcohol gradient, cleared by incubation in xylene, and placed paraffin and blocked. We obtained serial coronal sections $(6 \mu \mathrm{m})$ of brain tissue by a microtome (Leica RM2135, Germany). For assessing neural cell count and morphology, sections were stained with cresyl fast violet (Nissl). Briefly, after deparaffinization with xylene and rehydration with series of alcohol, tissues were stained with $0.1 \%$ cresyl violet (Sigma, Germany) for 5 min at RT. After several washes in distilled water and dehydration in alcohol series, slides were cleaned by xylene and mounted with entellan medium (Merck Chemicals, Germany). Slides were observed under the HUND microscope and Image J software was used for neural cell count. 


\section{Hematoxylin and Eosin (H\&E) Staining}

H\&E staining was used to assess neuronal injuries such as necrotic neurons and their structural changes. The brain sections were deparaffinized with xylene and rehydrated in alcohol series. Then, a hematoxylin stain was used for 5 minutes at RT. Following two washes and clearing in xylene, sections were counterstained with Eosine for $10 \mathrm{~min}$ at RT, and the cover slipped after several washes. Slides were observed under HUND Microscope. We captured pictures from the hippocampus in Dentate Gyrus (DG) and CA1-CA4 regions. Total and necrotic neurons were counted in the CA1-CA4 and dentate gyrus regions using the Image $\mathrm{J}$ software. Our images were analyzed from 3 sequential serial sections $(6 \mu \mathrm{m})$ in each slide, and we used three slides $(100 \mu \mathrm{m}$ interval) for each animal. We averaged 9 sections from each animal per group $(n=4)$. Altogether, 36 sections were analyzed for each experimental group.

\section{Quantitative Real-Time PCR (q-PCR)}

In this study, brain tissues of rats were dissected and collected in an RNA-later medium and kept at $4^{\circ} \mathrm{C}$ for some hours and then transported to $-20 \llbracket \mathrm{C}$ overnight. Then, the RNA-later solution was removed, and the samples were stored at $-80^{\circ} \mathrm{C}$ until processed for RNA extraction. Total RNA was extracted by an RNA extraction kit (A101231, Pars Tous, Iran). RNA concentration and quality were evaluated by nanodrop spectrophotometer (Thermo Scientific, Wilmington, DE USA), and then, the extracted RNA was immediately transferred to $-80 \mathbb{} \mathrm{C}$ freezer. We synthesized cDNA from $1 \mu \mathrm{g}$ of total RNA using a reverse transcription reagent kit with random hexamer primers as described by the manufacturer's protocol (A101161, Pars Tous, Mashhad). Oligo 7 software (version 7.60) and IDT online software were used to design specific primer sequences (forward and reverse primers) to identify the glial fibrillary acidic protein (GFAP) and Alpha-synuclein (a-Syn) as target genes and GAPDH as a reference gene. Primer sequences are listed in Table 2. Evaluation of mRNA expression was performed by real-time PCR using Real Q Plus Master Mix Green high rox (A325402, Amplicon, Denmark) and an ABI step-one plus real-time thermocycler ( $\mathrm{ABI}, \mathrm{USA})$. Briefly, real-time PCR was done by preparing $10 \mu \mathrm{l}$ of real-time PCR mix, with $0.25 \mu \mathrm{l}$ of each primer $(10 \mathrm{pmol} / \mu \mathrm{l}), 1 \mu \mathrm{l}$ of $\mathrm{CDNA}$, and $2.25 \mu \mathrm{l}$ of RNase free water. The initial denaturation step was $95^{\circ} \mathrm{C}$ for 15 min and then Forty cycles at $95^{\circ} \mathrm{C}$ for 15 secs, $62^{\circ} \mathrm{C}$ for 30 secs (annealing temperature), and $72{ }^{\circ} \mathrm{C}$ for $30 \mathrm{Sec}$ were exerted in PCR reaction. Finally, the melting curves of amplification were identified via heating the samples from 55 to $95^{\circ} \mathrm{C}$ at a linear rate of $0.2{ }^{\circ} \mathrm{C} / \mathrm{s}$. The 2delta-delta CT method was used for the static analysis of the relative expression level of mRNA (Table 2).

\section{Statistical Analysis}

Statistical analysis was performed using GraphPad Prism software (GraphPad Software, Version 7, USA). The result is reported as means \pm SEM. Repeated measure two-way analysis of variance (ANOVA) was used for analyzing the behavioral data in the training period. We used the one-way ANOVA followed by Tukey's post-hoc for analyzing the probe test data, histopathology, and qRT-PCR data. The p-value $<0.05$ was remarked as the minimum level of significance. 


\section{Results}

\section{Characterization of astrocyte cultures derived from neonatal mouse brains}

Primary cultures of astrocytes express important glial markers, such as GFAP, S100 S100- $\beta$, and GLAST proteins[32, 33]. Cell-isolated cultures were designated as a relatively pure culture after several passages. Most containing cells were astrocytes with a polygonal to fusiform and fat morphology (Fig 1, a). To confirm the efficacy of the isolation process and purity of astrocytes derived cultures, the immunofluorescence technique was used for GFAP, GLAST, and S100- $\beta$ antibodies. After 5 passages in vitro, most cells were highly expressed GFAP, GLAST, and S100- $\beta$ as specific astrocyte markers (Fig 1, bd). Thus, our isolated cells were purely astrocytes.

\section{TQ prevents NP-induced cytotoxicity in astrocytes culture}

To investigate the cytotoxicity of NP and TQ, primary astrocytes were treated with different concentrations of NP and TQ for 24 hours, and cell viability was assessed using the MTS assay. NP, at concentrations of $0.25-30 \mu \mathrm{M}$, did not noticeably affect cell viability. However, at higher concentrations from 40 to $100 \mu \mathrm{M}$, it demonstrated a significant cytotoxic effect on cells (all, $p<0.001$, Fig 2-a). The cells treated with TQ showed a reduction in cell viability in a dose-dependent manner compared to the control group. Treatment with 2.5-10 $\mu \mathrm{M}$ of TQ did not significantly reduce the cell viability. However, a noticeable decrease is demonstrated in doses of $12.5-20 \mu \mathrm{M}$ in comparison with the control group (all, $p<0.001$, Fig 2-b). Finally, combination of the most cytotoxic doses of NP and the most effective doses of TQ were examined in vitro. Our results showed that the number of viable cells in the NP40/TQ2.5 concentrations was more than that in the control group. Moreover, the number of viable cells in NP 40+ TQ 5, 7.5 and 10 $\mu \mathrm{M}$ was more than control, but the changes were not statistically significant. However, inset of NP (80 $\mu \mathrm{M}$ ) experiments, which was treated with different concentrations of TQ, more cell death was observed than that in the NP $40 \mu \mathrm{M}$ (Fig 2-C). Therefore, we can assume that TQ decreased the cytotoxic effect of NP in astrocyte cell culture.

\section{TQ attenuated learning and memory impairment in NP treated animals}

Several studies have reported that exposure to NP can lead to hippocampus injuries, including learning and memory impairment[34]. MWM task was performed to assess spatial learning and memory in different experimental groups. The averaged escape latency on 4 days of experimental trials was analyzed in different treatment groups as a spatial learning index. Spatial memory was assessed by a probe trial which was based on times that the rat spent in the target quadrant (Q4). Tukey post hoc analysis showed that the escape latency in the NP treated animals was considerably longer than that in the control group in the third $(p<0.0001)$ and fourth $(p<0.001)$ days of the training trials $($ Fig $3, a)$. On day 1 , TQ supplementation at a dose of $10 \mathrm{mg} / \mathrm{kg}$ and NP+TQ $(10 \mathrm{mg} / \mathrm{kg})$ decreased the escape compared to the NP group $(p=0.04)$. Other group's changes were not significant compared to the same day in the NP group. On day 2, TQ supplementation at doses of $2.5 \mathrm{mg} / \mathrm{kg}(\mathrm{p}=0.0001), 5,10 \mathrm{mg} / \mathrm{kg}(\mathrm{p}<0.0001)$ and TQ alone $(p<0.0001)$ decreased the escape latency compared to NP group. On day 3 , it has been observed 
that the escape latency index in NP+TQ $(2.5 \mathrm{mg} / \mathrm{kg}, \mathrm{p}=0.002)$ and NP+TQ $(5 \mathrm{mg} / \mathrm{kg}, p<0.0001)$ was noticeably shorter than that in the NP group. On day 4, escape latency in NP+TQ $(2.5 \mathrm{mg} / \mathrm{kg}, \mathrm{p}=0.016)$, NP+TQ (5mg/kg, $\mathrm{p}=0.001)$, NP+TQ (10 mg/kg, $\mathrm{p}=0.007)$ and TQ $(10 \mathrm{mg} / \mathrm{kg}, \mathrm{p}=0.01)$ was considerably reduced compared to NP group (Fig $3, \mathrm{~b})$.

In the control group, the escape latency index at days $3,4(p<0.0001)$ was significantly decreased compared to the first day of the experimental trial, but this pattern was not seen in the NP group (Fig 3, a). Moreover, comparison within NP+TQ $(2.5 \mathrm{mg} / \mathrm{kg})$ group showed that the escape latency on day $2(\mathrm{p}=$ $0.037), 3(p=0.003)$ and 4 ( $p<0.001)$ was reduced compared to the first training day. In NP+TQ $(5 \mathrm{mg} / \mathrm{kg})$ group, a significant reduction in escape latency has been seen on days 2, 3 and 4 compared to the first day $(\mathrm{p}<0.0001)$. In addition, in NP+TQ $(10 \mathrm{mg} / \mathrm{kg})$ group, escape latency was decreased on the second, third, and fourth days $(p<0.0001)$ compared to the first day of training trials. Moreover, in the NP+TQ $(10 \mathrm{mg} / \mathrm{kg})$ group, the escape latency on days $2(p=0.011), 3$, and $4(p<0.0001)$ was shorter than that on the first day of training. Also, in the TQ $(10 \mathrm{mg} / \mathrm{kg})$, there was a significant reduction in escape latency on day 3 compared to day 1 ( $p<0.001$, Fig3-b).

For evaluation of spatial memory, the platform was removed at the end of the experiment after four days training period. The time spent in the target quadrant (Q4) was measured and analyzed in all experimental groups. The analysis showed that NP treated animals spent less time in Q4 than that in the control group ( $p<0.0001)$. TQ treatment at the $5 \mathrm{mg} / \mathrm{kg}$ dose significantly enhanced the time spent in the target quadrant compared to the NP group ( $p<0.05$, Fig 4-c). Furthermore, no significant changes were seen in swimming velocity after NP and TQ treatments through the experiment. Thus TQ improved learning and memory function in NP-treated animals.

\section{TQ reduced oxidative stress and enhanced total antioxidant capacity in NP treated animals}

To evaluate the antioxidant effects of TQ on NP-induced oxidative stress, TAC, MDA, SOD, and GSH, was assessed based on their kit instructions. The total antioxidant capacity $(T A C)$ in tissue $(p<0.0001)$ and serum $(p<0.001)$ level was considerably reduced in the NP group compared to the control group ( $p<0.0001$, Fig4-a). Tissue TAC level in NP+ TQ (2.5mg/kg, $p<0.05), N P+T Q(5 \mathrm{mg} / \mathrm{kg}, p<0.01), N P+$ TQ $(10 \mathrm{mg} / \mathrm{kg}, \mathrm{p}<0.01)$ groups, significantly increased compared to NP groups (Fig4-a). Moreover, serum TAC level in all TQ treated groups was higher than that in NP group but the changes was only statistically significant in NP+TQ $(5 \mathrm{mg} / \mathrm{kg}, \mathrm{p}<0.01)$ group (Fig4-b). Our results showed that MDA levels in serum $(p<0.001)$ and tissue $(p<0.0001)$ were significantly increased the NP group compared to the control group (Fig4-c). Tissue MDA level in NP+TQ (5mg/kg), NP+TQ (10mg/kg), and TQ (10mg/kg) groups was significantly reduced compared to NP group ( $p<0.05$, Fig4-c). However, no significant difference was observed in serum MDA level in TQ treated groups compared to the NP group (Fig4-d). In NP group the serum SOD level was significantly higher than that in the control group $(p<0.0001$, Fig4-f). However, SOD level significantly increased in NP+TQ $(5 \mathrm{mg} / \mathrm{kg})$ and NP+TQ $(10 \mathrm{mg} / \mathrm{kg})$ groups compared to NP group (Fig4-f). Biochemical analysis for GSH level indicated that NP significantly decreased the GSH level compared to the control group $(\mathrm{p}<0.0001)$. But, GSH level was significantly increased in NP+TQ $(5 \mathrm{mg} / \mathrm{kg}$, 
$\mathrm{p}<0.05)$ and NP+TQ $(10 \mathrm{mg} / \mathrm{kg}, \mathrm{p}<0.001)$ groups compared to NP group. Thus, TQ enhanced the antioxidant capacity of the CNS by increasing antioxidant factors and reducing oxidative markers.

\section{The neuroprotective effect of TQ decreased NP-Induced neural injury in the hippocampus}

To evaluate the neuroprotective effect of TQ, the hippocampal regions were analyzed by H\&E (Fig.5) and Nissl (Fig.6) staining. We found that the total number of neurons in the NP-treated group was less than that in the control group both in DG $(140.63 \pm 4.91, p<0.0001)$ and CA1-CA4 $(120.3 \pm 2.59, p<0.0001)$ regions (Table3). Moreover, no significant difference was observed in the total number of neurons between TQ treated and NP groups. The population of necrotic neurons was shown as a percentage of the total number of neurons counted in the DG and CA1-CA4 regions of the hippocampus (Table3). Our results showed that the percentage of necrotic neurons in NP-treated group was significantly higher than that in the control group in both DG $(12.53 \%, \mathrm{p}<0.001)$ and CA1-CA4 $(9.59 \%, \mathrm{p}<0.0001)$ regions. However, TQ treatment in NP+TQ $(2.5 \mathrm{mg} / \mathrm{kg})$ group, decreased the percentage of necrotic neurons in DG $(7.28 \%$, $p<0.01)$ and CA1-CA4 $(5.85 \%, p<0.001)$ regions compared to the NP group. Moreover, percentage of necrotic neurons were considerably reduced in NP+TQ $(5 \mathrm{mg} / \mathrm{kg})$ in DG $(6.31 \%, \mathrm{p}<0.001)$ and CA1-CA4 $(4.88 \%, p<0.001)$ and in TQ $(10 \mathrm{mg} / \mathrm{kg})$ group in CA1-CA4 $(4.86 \%, \mathrm{p}<0.01)$ compared to NP group. Therefore, it can be concluded that TQ treatment has neuroprotective effect against NP induced brain injuries such as necrosis and neuronal loss.

\section{TQ reduced the expression level of GFAP and enhanced a-Syn in NP treated groups}

Upregulation of GFAP expression (as astrocyte marker) indicates gliosis and glial activation[35]. To evaluate CNS gliosis, we assessed GFAP expression. Results showed that administration of NP at the dose of $25 \mathrm{mg} / \mathrm{kg}$ significantly increased the GFAP gene expression compared to the control group $(\mathrm{p}<$ 0.01, Fig7-a). TQ treatment downregulated the level of GFAP in NP+TQ $(2.5 \mathrm{mg} / \mathrm{kg}, p<0.05), N P+T Q(5$ $\mathrm{mg} / \mathrm{kg}, \mathrm{p}<0.01)$ and NP+TQ $(10 \mathrm{mg} / \mathrm{kg}, \mathrm{p}<0.01)$ groups compared to NP group (Fig7-a). a-Syn is a protein that has a key role in neurotransmitter release and synaptic plasticity[36]. Over-expression of the a-Syn gene can lead to a-Syn neuronal inclusions that causes neurodegeneration [37]. Our results have shown that the a-Syn expression was upregulated in the NP group compared to the control group $(p=0.004)$. Moreover, $T Q$ treatment significantly downregulated the $a-S y n$ expression level in all groups but, changes were statically significant only in NP+TQ $(5 \mathrm{mg} / \mathrm{kg}, \mathrm{p}<0.01)$ and TQ $(10 \mathrm{mg} / \mathrm{kg}, \mathrm{p}<0.01)$ compared to NP group (Fig7-b). Our results confirmed that TQ significantly reduced the expression of GFAP and a-Syn following NP-induced neurotoxicity.

\section{Discussion}

We investigated whether TQ can be a beneficial compound on the NP-induced neurotoxicity in an animal model. We observed that treatment with TQ reduces NP-induced cytotoxicity in vitro. Subsequently, TQ prevented neurotoxicity symptoms and improves memory deficit induced by NP. Moreover, TQ increased antioxidant parameters such as TAC, GSH, and SOD and reduced MDA as an oxidative stress marker. Histological study indicated that the number of necrotic cells in TQ treated groups was significantly 
decreased in hippocampal regions compared to NP-treated animals. Finally, we found that treatment with TQ reduced GFAP and a-Syn expression level. The findings indicate that TQ is effective treatment for NP neurotoxicity through its antioxidant, neuroprotective and anti-inflammatory effects.

There have been growing concerns about persistent organic pollutants (POPs) toxicity on the CNS in recent years, such as morphological and physiological changes[38]. Numerous investigations have evidenced that perinatal exposure to POPs can lead to learning and memory damage in rats[39]. NP as a potent POP has been demonstrated to be potentially neurotoxic which, leads to spatial memory and cognitive impairment in animal models[34]. In this study, we used NP to induce learning and memory impairment as an animal model. Previous study demonstrated that developmental exposure to NP induces axonal damage in the developing neurons in vitro and in vivo[40]. Another study indicated that according to MWM task results, exposure to NP causes memory and learning deficit[41, 42]. Based on a study, the neurotoxicity of NP may be owing to the activation of inflammatory and oxidative stress signaling, which stimulate the expression of inflammatory mediators. Moreover, NP activates MG which causes neuroinflammation following upregulating of GFAP gene expression[17].

In the present study, we observed that NP reduced cell survival and induces cell toxicity. In parallel with our research, it has been reported that exposure to NP induced apoptosis and decreases cell viability in primary cortical neurons[43]. Another study has demonstrated that NP induces cytotoxicity through apoptosis by the cell cycle arrest and the caspase cascade[44]. To better understand the interactions between NP toxicity and TQ neuroprotection, we administered different doses of NP and TQ to treat astrocyte cultured cells and evaluate the cell viability during NP cytotoxicity by MTP test. We observed that TQ protected astrocytes from cytotoxicity induced by NP. In line with our data, it has been reported that TQ $(0.01,0.1,1$, and $10 \mu \mathrm{M})$ protected neurons against 1-methyl-4-phenylpyridinium (MPP) by inhibiting cell death and maintaining mitochondrial function[45]. Another study demonstrated that TQ as a strong neuroprotective agent protects primary rat cortical neurons against ethanol-induced neuronal apoptosis [23]. Moreover, it was evident that pretreatment with TQ inhibited neurotoxicity induced by betaamyloid in primary cultured neurons cell death [46]. These results confirmed that TQ has neuroprotective properties against several in vitro neurotoxicity models.

We showed that NP reduced learning and memory ability based on MWM task results. MWM task as a valid test is widely uses to evaluate learning and memory function in rodents[31]. Several studies have demonstrated that NP disrupts oxidant/antioxidant balance and causes neurotoxicity results in, cognitive deficits and memory impairments in the animal[9, 42]. Our biochemical results showed that the brain level of MDA increased in NP-treated group. MDA is commonly known as a marker of oxidative injury. On the other hand, NP decreased the level of TAC, SOD, and GSH. Our data in line with other studies indicated that oxidative damages can be considered as one of mechanisms of NP to induce neurotoxicity. In parallel with our research, it has been reported that NP increased brain MDA levels and decreased the activity of SOD, CAT in mice[47]. Several studies have suggested that NP induces apoptosis and necrosis in neurons $[12,48]$. We found that the number of necrotic cells in the NP-treated group was increased compared to the other groups. In line with other studies We also found that NP causes neurotoxicity 
through misbalancing oxidant/antioxidant mediators and induction of apoptosis and necrosis in neuronal cells which were accompanied by learning and deficit memory.

TQ has various therapeutic properties such as antioxidant[49], anti-inflammatory, and anti-cancer effects[50]. The learning process during the MWM task in our study has significantly improved in all TQ treatment groups compared to the NP-treated group. Furthermore, TQ treatment specifically at dose $(5 \mathrm{mg} / \mathrm{kg})$ considerably enhanced memory function in the probe task. TQ is considered as a potent neuroprotective compound to protect neurons from degeneration in a different model of neurotoxicity [51, 52]. Consistent with our results, a research study reported that $T Q$ at doses ( 15 and $7.5 \mathrm{mg} / \mathrm{kg}$ ) had effective effects in rotenone-induced animal model of Parkinson's diseases. Moreover, they showed that TQ significantly improved the neuronal damage caused by rotenone toxin in the Parkinson's model[53]. It is also reported that TQ had protective effect of on neurotoxicity induced by lipopolysaccharide (LPS) at doses of 2, 5 , or $10 \mathrm{mg} / \mathrm{kg}$ and improved learning and memory function in LPS treated animals[26]. Moreover, the protective effects of TQ at doses $(10,20,40 \mathrm{mg} / \mathrm{kg})$ were reported in the Aluminum chloride-induced animal model of Alzheimer's disease. They found that TQ can reduce betaamyloid formation and improve animal learning and memory performance in MWM test[54]. Therefore, our data in line with above mentioned studies supported that TQ possesses a potent antioxidant and neuroprotective properties that enhance learning and memory impairments in our animal model. To realize the therapeutic mechanisms of TQ, we investigated several mechanisms such as cell survival, oxidative stress, the expression of GFAP and a-Syn and histopathology. Our results also indicated that TQ could reduce glial activation, oxidative damage, and inflammation induced by NP, which might contribute to its effect on learning and memory improvement.

Oxidative stress has a crucial role in neurodegeneration progression[55]. MDA is indicated as an index of lipid peroxidation, is an outcome of free oxygen radicals induced oxidative degeneration[56]. The current study showed that the brain level of MDA significantly increased in the NP-treated group. Several studies have reported that oxidative stress is one of the main mechanisms of NP toxicity and various neurological diseases[57, 58]. We found that TQ significantly decreased the brain MDA level and increased antioxidant status. The central cellular antioxidant defense is enzymatic, including glutathione peroxidase (cGPx), SOD, and catalase (CAT). GSH is the essential non-enzymatic antioxidant defense that protects cells from reactive oxygen species attacks. GSH measurement of the brain was performed due to the critical role of this molecule in maintaining the balance of oxidative stress. The brain is very vulnerable to oxidative stress because it is an organ rich with unsaturated fats. Moreover, disturbing the brain's antioxidant system causes oxidative stress and subsequently some neurodevelopmental and neurodegenerative diseases $[59,60]$. In the present study, we found that TQ increased brain and serum antioxidant defense by enhancing SOD, GSH, and TAC level. A large body of evidence confirms that TQ, as a potent antioxidant, increases antioxidant capacity of the brain tissue and protects brain cells from various injuries due to its antioxidant, anti-inflammatory, and apoptotic effects[61]. Our study showed that NP attenuated the brain antioxidant capacity and TQ treatment modulated antioxidant levels by increasing total antioxidant capacity. In agreement with our findings, several studies have reported that TQ possesses a potent antioxidant and neuroprotective properties[49, 51]. It was also reported that TQ 
reduces arsenic-induced neurotoxicity at a dose of $10 \mathrm{mg} / \mathrm{kg}$. They showed TQ significantly decreased MDA level and increased the level of SOD, GSH, and CAT in the arsenic-treated groups[62]. Moreover, it was confirmed that TQ at doses ( 5 and $10 \mathrm{mg} / \mathrm{kg}$ ) significantly decreased the levels of MDA and enhanced the GSH levels after administration of Acrylamide[63]. Thus, antioxidant property of TQ can be considered as one of the protective mechanisms against learning and memory impairment in our model.

Histopathological evaluation of the rat hippocampus indicated some pathological changes including necrotic cells and cell loss in the hippocampus of NP-treated rats compared to the control group. Recently, it has been shown that NP induces apoptosis and necrosis in neuronal cells by stimulating inflammatory and apoptotic factors[64]. An earlier studies demonstrated that TQ improves brain tissue injury through enhancement of neurogenesis in the hippocampus[65]. Pervious study revealed that TQ and Nigella Sativa improved hippocampal neuronal pathology induced by toluene exposure in the rat model[66]. In agreement with previous reports, our data indicated that in TQ treatment reduced the necrotic neuron densities in NP-treated animals. TQ neutralized the oxidative stress factors, gliosis and improved the neuronal survival. Altogether, it can be assuming that TQ is a neuroprotective agent and enhanced cognitive function in the model of NP-induced neurotoxicity.

GFAP is a protein expressed by various nerve cells, especially in astrocytes, during evolution and development and is considered a sensitive and critical marker of astrocytes. Hence, any change in GFAP can be a marker of astrocyte damage[67]. Since another symptom of NP neurotoxicity is gliosis, especially MG and astrocytes reactivation, we assessed GFAP gene expression in different experimental groups. Nerve damage and infection in the CNS trigger MG and astrocytes activations. During brain damage and neurodegenerative disorders, astrocytes undergo a series of morphological changes that lead to the activation of the inflammatory state, an increase in the number of astrocytes, and the expression of the GFAP gene that called astrogliosis[68]. It was reported that NP induces the GFAP overexpression and astrogliosis[69]. In line with these reports, we observed a significant increase in GFAP gene expression in the NP group compared to other groups. In addition to astrocyte, several studies indicated that exposure to different doses of NP affects the number and function of glial cells[17]. Besides, it was demonstrated that TQ $(5 \mathrm{mg} / \mathrm{kg})$ significantly reduced the GFAP expression in Acrylamide treated animals[63]. In agreement with this report, we showed that TQ at doses 5 and $10 \mathrm{mg} / \mathrm{kg}$ significantly decreased the expression level of GFAP in the NP treated groups. This beneficial effect of TQ to attenuate GFAP gene expression can be considered as its anti-inflammatory properties.

a-Syn is a small peripheral membrane protein explicitly found in the axon terminal in neurons, indicating a critical role in neurotransmitter release[70] and synaptic plasticity[71]. It has been reported that the loss of a-Syn has little effect on synaptic transmission, while over-expression of this gene causes cognitive dysfunction in Parkinson's (PD) and Alzheimer Diseases[72]. Several lines of evidence supported that TQ effectively protected cultured hippocampal neurons against a-Syn -induced synapse damage and interference in regular synaptic activity[73]. Another study discussed the protective effects of TQ in the MPTP induced Parkinson's model was due to a-Syn modulation. They showed that TQ prevents accumulations of a-Syn protein at the axon terminal of neurons[63]. Consistent with this report, we 
indicated that a-Syn gene expression in the rat brain was upregulated after NP exposure and TQ significantly downregulated the expression of a-Syn in NP-treated groups. Over-expression of the a-Syn gene can lead to the formation of toxic filamentous and a-Syn neuronal inclusions, which causes neurodegeneration[37]. Moreover, abnormal accumulation and aggregation of a-Syn in the form of Lewy bodies and neurites causes dopaminergic neuronal cells loss in the substantia nigra as landmark in PD[74]. Together, it can be concluded that NP interrupts synaptic plasticity by upregulating a-Syn and TQ reduced the expression of a-Syn and enhanced synaptic plasticity and learning and memory function in NP exposed animals.

\section{Conclusion}

To sum up all the outcomes, the present study indicated that TQ has therapeutic potential to improve learning and memory impairment through its anti-inflammatory, neuroprotective, and antioxidant properties. It seems that the therapeutic effects of $T Q$ are associated with reduction of gliosis, oxidative damage, and inflammatory mediators. Further study is needed to prove the exact underlying mechanisms of TQ as a hopeful therapeutic target in NP neurotoxicity. Upcoming clinical trials will provide deeper insights into the role of TQ as a useful compound for learning and memory improvement in order to develop strategies to better follow and treat these kinds of NP neurotoxic effects.

\section{Declarations}

\section{Acknowledgment}

The authors wish to express their sincere gratitude to Ms. Fatemeh Shirafkan for her help in Quantitative Real-Time reaction analysis. Also, the authors wish to thank the Vice-chancellor of Research and Technology of Babol University of Medical Sciences for supporting this study.

\section{Ethical approval}

All experiments and procedures of this study were reviewed and approved by the Research Ethics Committees of Babol University of Medical Sciences (IR.MUBABOL.REC.1398.026).

\section{Compliance with Ethical Standards}

Ethical Approval All experiments and procedures of this study were reviewed and approved by the Research Ethics Committees of Babol University of Medical Sciences (IR.MUBABOL.REC.1398.026).

Consent to Participate Not applicable.

Consent for Publication The consent to publish this manuscript has been obtained from all authors.

Conflict of Interest The authors declare that they have no conflict of interest. 
Author contributions: M. Lotfi, A. Eghbali and A. Ebrahimpour performed the experiments, collected and analyzed data, and contributed to experimental design. S. Kazemi, F. Pourabdolhossein and S. L. Satarian contributed to experimental design and its implementation. A. A. Moghadamnia, M. Lotfi, and F. Pourabdolhossein contributed to the interpretation of the data and wrote preliminary draft of the manuscript. A. A. Moghadamnia and S. Kazemi supervised the experiments. All authors read and approved the final manuscript.

Funding: This work was supported by a grant (9808809) from Babol University of Medical Sciences.

Data Availability: Data are available from the authors upon request

\section{References}

1. Diamanti-Kandarakis E, ... JB-E, 2009 undefined (2009) Endocrine-disrupting chemicals: an Endocrine Society scientific statement. academic.oup.com. https://doi.org/10.1210/er.2009-0002

2. Pinson A, Bourguignon J, Andrology AP-, 2016 undefined (2016) Exposure to endocrine disrupting chemicals and neurodevelopmental alterations. Wiley Online Libr 4:706-722. https://doi.org/10.1111/andr.12211

3. Chokwe TB, Okonkwo JO, Sibali LL (2017) Distribution, exposure pathways, sources and toxicity of nonylphenol and nonylphenol ethoxylates in the environment. Water SA 43:529-542. https://doi.org/10.4314/wsa.v43i4.01

4. Kim H, Oh S, Gye MC, Shin I (2018) Comparative toxicological evaluation of nonylphenol and nonylphenol polyethoxylates using human keratinocytes. Drug Chem Toxicol 41:486-491. https://doi.org/10.1080/01480545.2017.1391829

5. Monteiro-Riviere NA, Van Miller JP, Simon G, et al (2000) Comparative in vitro percutaneous absorption of nonylphenol and nonylphenol ethoxylates (NPE-4 and NPE-9) through human, porcine and rat skin. Toxicol Ind Health 16:49-57. https://doi.org/10.1177/074823370001600201

6. Sciarrillo R, Di Lorenzo M, Valiante S, et al (2021) OctylPhenol (OP) Alone and in Combination with NonylPhenol (NP) Alters the Structure and the Function of Thyroid Gland of the Lizard Podarcis siculus. Arch Environ Contam Toxicol 80:567-578. https://doi.org/10.1007/s00244-021-00823-5

7. Geens T, Neels H, Covaci A (2012) Distribution of bisphenol-A, triclosan and n-nonylphenol in human adipose tissue, liver and brain. Chemosphere 87:796-802.

https://doi.org/10.1016/j.chemosphere.2012.01.002

8. Vivacqua A, Recchia AG, Fasanella G, et al (2003) The Food Contaminants Bisphenol A and 4Nonylphenol Act as Agonists for Estrogen Receptor a in MCF7 Breast Cancer Cells. Endocrine 22:275284. https://doi.org/10.1385/END0:22:3:275 
9. Mao Z, Zheng YL, Zhang YQ (2011) Behavioral impairment and oxidative damage induced by chronic application of nonylphenol. Int J Mol Sci 12:114-127. https://doi.org/10.3390/ijms12010114

10. Jie X, Li JM, Zheng F, et al (2013) Neurotoxic effects of nonylphenol: A review. Wien Klin Wochenschr 125:61-70. https://doi.org/10.1007/s00508-012-0221-2

11. Arukwe A, Thibaut R émi, Ingebrigtsen $\mathrm{K}$, et al (2000) In vivo and in vitro metabolism and organ distribution of nonylphenol in Atlantic salmon (Salmo salar). Aquat Toxicol 49:289-304. https://doi.org/10.1016/S0166-445X(99)00084-3

12. Gu W, Wang Y, Qiu Z, et al (2018) Maternal exposure to nonylphenol during pregnancy and lactation induces microglial cell activation and pro-inflammatory cytokine production in offspring hippocampus. Sci Total Environ 634:525-533. https://doi.org/10.1016/j.scitotenv.2018.03.329

13. Korkmaz A, Ahbab MA, Kolankaya D, Barlas N (2010) Influence of vitamin C on bisphenol A, nonylphenol and octylphenol induced oxidative damages in liver of male rats. Food Chem Toxicol 48:2865-2871. https://doi.org/10.1016/j.fct.2010.07.019

14. Eid Z, Mahmoud UM, Mekkawy IAA, et al (2021) 4-Nonylphenol induced brain damage in juvenile African catfish (Clarias garepinus). Toxicol Environ Health Sci 13:201-214. https://doi.org/10.1007/s13530-021-00080-y

15. Tabassum H, Ashafaq M, Parvez S, Raisuddin S (2017) Role of melatonin in mitigating nonylphenol-induced toxicity in frontal cortex and hippocampus of rat brain. Neurochem Int 104:11-26. https://doi.org/10.1016/j.neuint.2016.12.010

16. Asifa KP, Chitra KC (2016) Impact of Nonylphenol on Antioxidant System and Acetylcholinesterase Activity in the Brain of Etroplus Maculatus (Bloch, 1795). Int J Res Available

17. Qiu Z, Wang Y, Chen J (2019) Perinatal exposure to nonylphenol induces microglia-mediated nitric oxide and prostaglandin E2 production in offspring hippocampus. Toxicol Lett 301:114-124. https://doi.org/10.1016/j.toxlet.2018.11.013

18. Rehman MU, Wali AF, Ahmad A, et al (2018) Neuroprotective Strategies for Neurological Disorders by Natural Products: An update. Curr Neuropharmacol 17:247-267.

https://doi.org/10.2174/1570159x16666180911124605

19. Ahmad MF, Ahmad FA, Ashraf SA, et al (2021) An updated knowledge of Black seed (Nigella sativa Linn.): Review of phytochemical constituents and pharmacological properties. J Herb Med 25:. https://doi.org/10.1016/j.hermed.2020.100404

20. El Gazzar M, El Mezayen R, Marecki JC, et al (2006) Anti-inflammatory effect of thymoquinone in a mouse model of allergic lung inflammation. Int Immunopharmacol 6:1135-1142. https://doi.org/10.1016/j.intimp.2006.02.004 
21. Darakhshan S, Bidmeshki Pour A, Hosseinzadeh Colagar A, Sisakhtnezhad S (2015)

Thymoquinone and its therapeutic potentials. Pharmacol Res 95-96:138-158.

https://doi.org/10.1016/j.phrs.2015.03.011

22. Cobourne-Duval MK, Taka E, Mendonca P, et al (2016) The Antioxidant Effects of Thymoquinone in Activated BV-2 Murine Microglial Cells. Neurochem Res 41:3227-3238.

https://doi.org/10.1007/s11064-016-2047-1

23. Ullah I, Ullah N, Naseer Ml, et al (2012) Neuroprotection with metformin and thymoquinone against ethanol-induced apoptotic neurodegeneration in prenatal rat cortical neurons. BMC Neurosci 13:. https://doi.org/10.1186/1471-2202-13-11

24. Alemi M, Sabouni F, Sanjarian F, et al (2013) Anti-inflammatory effect of seeds and Callus of Nigella sativa L. extracts on mix glial cells with regard to their thymoquinone content. AAPS PharmSciTech 14:160-167. https://doi.org/10.1208/s12249-012-9899-8

25. Poorgholam P, Yaghmaei P, Hajebrahimi Z Thymoquinone recovers learning function in a rat model of Alzheimer's disease. Avicenna J phytomedicine 8:188-197.

https://doi.org/10.22038/ajp.2018.21828.1820

26. Bargi R, Asgharzadeh F, Beheshti F, et al The effects of thymoquinone on hippocampal cytokine level, brain oxidative stress status and memory deficits induced by lipopolysaccharide in rats. Elsevier

27. Ebrahimi SS, Oryan S, Izadpanah E, Hassanzadeh K (2017) Thymoquinone exerts neuroprotective effect in animal model of Parkinson's disease. Toxicol Lett 276:108-114.

https://doi.org/10.1016/j.toxlet.2017.05.018

28. Zarei-Kheirabadi M, Mirsadeghi S, Vaccaro AR, et al (2020) Protocol for purification and culture of astrocytes: useful not only in 2 days postnatal but also in adult rat brain. Mol Biol Rep 47:1783-1794. https://doi.org/10.1007/s11033-020-05272-2

29. Malich G, Markovic B, Toxicology CW-, 1997 undefined The sensitivity and specificity of the MTS tetrazolium assay for detecting the in vitro cytotoxicity of 20 chemicals using human cell lines. Elsevier

30. Hosseinzadeh H, Parvardeh S, AsI MN, et al (2007) Effect of thymoquinone and Nigella sativa seeds oil on lipid peroxidation level during global cerebral ischemia-reperfusion injury in rat hippocampus. Phytomedicine 14:621-627. https://doi.org/10.1016/j.phymed.2006.12.005

31. D'Hooge R, De Deyn PP (2001) Applications of the Morris water maze in the study of learning and memory. Brain Res Rev 36:60-90. https://doi.org/10.1016/S0165-0173(01)00067-4

32. Duan S, Anderson CM, Stein BA, Swanson RA (1999) Glutamate induces rapid upregulation of astrocyte glutamate transport and cell-surface expression of GLAST. J Neurosci 19:10193-10200. 
33. Donato R, Sorci G, Riuzzi F, et al (2009) S100B's double life: Intracellular regulator and extracellular signal. Biochim Biophys Acta - Mol Cell Res 1793:1008-1022. https://doi.org/10.1016/j.bbamcr.2008.11.009

34. Kazemi S, Khalili-Fomeshi M, Akbari A, et al (2018) The correlation between nonylphenol concentration in brain regions and resulting behavioral impairments. Brain Res Bull 139:190-196. https://doi.org/10.1016/j.brainresbull.2018.03.003

35. Brahmachari S, Fung YK, Pahan K (2006) Induction of glial fibrillary acidic protein expression in astrocytes by nitric oxide. J Neurosci 26:4930-4939. https://doi.org/10.1523/JNEUROSCI.5480-05.2006

36. Cheng F, Vivacqua G, Yu S (2011) The role of alpha-synuclein in neurotransmission and synaptic plasticity. J Chem Neuroanat 42:242-248. https://doi.org/10.1016/j.jchemneu.2010.12.001

37. Desplats $\mathrm{P}$, Spencer B, Crews $\mathrm{L}$, et al (2012) a-Synuclein induces alterations in adult neurogenesis in Parkinson disease models via p53-mediated repression of notch. J Biol Chem 287:31691-31702. https://doi.org/10.1074/jbc.M112.354522

38. Doucet J, Tague B, Arnold DL, et al (2009) Persistent organic pollutant residues in human fetal liver and placenta from greater Montreal, Quebec: A longitudinal study from 1998 through 2006. Environ Health Perspect 117:605-610. https://doi.org/10.1289/ehp.0800205

39. Tiwari SK, Agarwal S, Chauhan LKS, et al (2015) Bisphenol-A Impairs Myelination Potential During Development in the Hippocampus of the Rat Brain. Mol Neurobiol 51:1395-1416. https://doi.org/10.1007/s12035-014-8817-3

40. Li S, You M, Chai W, et al (2019) Developmental exposure to nonylphenol induced rat axonal injury in vivo and in vitro. Arch Toxicol 93:2673-2687. https://doi.org/10.1007/s00204-019-02536-0

41. Jie X, Yang W, Jie Y, et al (2010) Toxic effect of gestational exposure to nonylphenol on F1 male rats. Birth Defects Res Part B - Dev Reprod Toxicol 89:418-428. https://doi.org/10.1002/bdrb.20268

42. Li M, You M, Li S, et al (2019) Effects of maternal exposure to nonylphenol on learning and memory in offspring involve inhibition of BDNF-PI3K/Akt signaling. Brain Res Bull 146:270-278. https://doi.org/10.1016/j.brainresbull.2019.01.014

43. Kim SK, Kim BK, Shim JH, et al (2006) Nonylphenol and octylphenol-induced apoptosis in human embryonic stem cells is related to Fas-Fas ligand pathway. Toxicol Sci 94:310-321. https://doi.org/10.1093/toxsci/kfl14

44. Kudo C, Wada K, Masuda T, et al (2004) Nonylphenol induces the death of neural stem cells due to activation of the caspase cascade and regulation of the cell cycle. J Neurochem 88:1416-1423. 
45. Radad K, Al-Shraim M, ... MM-N, 2015 undefined (2013) Neuroprotective role of thymoquinone against 1-methyl-4-phenylpyridinium-induced dopaminergic cell death in primary mesencephalic cell culture. nsj.org.sa

46. Ismail $\mathrm{N}$, Ismail M, Mazlan $\mathrm{M}$, et al (2013) Thymoquinone prevents $\beta$-amyloid neurotoxicity in primary cultured cerebellar granule neurons. Cell Mol Neurobiol 33:1159-1169. https://doi.org/10.1007/s10571-013-9982-z

47. Korkmaz A, Ahbab MA, Kolankaya D, Barlas N (2010) Influence of vitamin C on bisphenol A, nonylphenol and octylphenol induced oxidative damages in liver of male rats. Food Chem Toxicol 48:2865-2871. https://doi.org/10.1016/j.fct.2010.07.019

48. Mao Z, Zheng Y, Zhang Y, et al (2008) Chronic application of nonylphenol-induced apoptosis via suppression of bcl-2 transcription and up-regulation of active caspase-3 in mouse brain. Neurosci Lett 439:147-152. https://doi.org/10.1016/j.neulet.2008.05.006

49. Staniek K, Gille L (2010) Is thymoquinone an antioxidant? BMC Pharmacol 10:. https://doi.org/10.1186/1471-2210-10-s1-a9

50. Woo CC, Kumar AP, Sethi G, Tan KHB (2012) Thymoquinone: Potential cure for inflammatory disorders and cancer. Biochem Pharmacol 83:443-451. https://doi.org/10.1016/j.bcp.2011.09.029

51. Isaev NK, Chetverikov NS, Stelmashook E V., et al (2020) Thymoquinone as a Potential Neuroprotector in Acute and Chronic Forms of Cerebral Pathology. Biochem 85:167-176. https://doi.org/10.1134/S0006297920020042

52. Abulfadl YS, El-Maraghy NN, Ahmed AAE, et al (2018) Protective effects of thymoquinone on Dgalactose and aluminum chloride induced neurotoxicity in rats: biochemical, histological and behavioral changes. Neurol Res 40:324-333. https://doi.org/10.1080/01616412.2018.1441776

53. Radad K, Moldzio R, Taha M, Rausch WD (2009) Thymoquinone protects dopaminergic neurons against MPP+ and rotenone. Phyther Res 23:696-700. https://doi.org/10.1002/ptr.2708

54. Abulfadl YS, El-Maraghy NN, Ahmed AAE, et al (2018) Thymoquinone alleviates the experimentally induced Alzheimer's disease inflammation by modulation of TLRs signaling. Hum Exp Toxicol 37:1092-1104. https://doi.org/10.1177/0960327118755256

55. Federico A, Cardaioli E, Da Pozzo P, et al (2012) Mitochondria, oxidative stress and neurodegeneration. J Neurol Sci 322:254-262. https://doi.org/10.1016/j.jns.2012.05.030

56. Ayala A, Muñoz MF, Argüelles S (2014) Lipid peroxidation: Production, metabolism, and signaling mechanisms of malondialdehyde and 4-hydroxy-2-nonenal. Oxid Med Cell Longev 2014:. 
57. Lotfi M, Hasanpour AH, Moghadamnia AA, Kazemi S (2020) The Investigation into Neurotoxicity Mechanisms of Nonylphenol: A Narrative Review. Curr Neuropharmacol 19:1345-1353. https://doi.org/10.2174/1570159x18666201119160347

58. Floyd RA (1999) Antioxidants, oxidative stress, and degenerative neurological disorders. Proc Soc Exp Biol Med 222:236-245. https://doi.org/10.1046/j.1525-1373.1999.d01-140.x

59. Bjørklund G, Meguid NA, El-Bana MA, et al (2020) Oxidative Stress in Autism Spectrum Disorder. Mol Neurobiol 57:2314-2332. https://doi.org/10.1007/s12035-019-01742-2

60. Ye J, Zhai HZ (2005) Oxidative stress and Alzheimer disease. Chinese J Clin Rehabil 9:117-119 61. Banerjee S, Padhye S, Azmi A, et al (2010) Review on molecular and therapeutic potential of thymoquinone in cancer. Nutr Cancer 62:938-946. https://doi.org/10.1080/01635581.2010.509832

62. Kassab R, Applied RE-H-EJ of B and, 2017 undefined The role of thymoquinone as a potent antioxidant in ameliorating the neurotoxic effect of sodium arsenate in female rat. Elsevier

63. Tabeshpour J, Mehri S, Abnous K, Hosseinzadeh H (2020) Role of Oxidative Stress, MAPKinase and Apoptosis Pathways in the Protective Effects of Thymoquinone Against Acrylamide-Induced Central Nervous System Toxicity in Rat. Neurochem Res 45:254-267. https://doi.org/10.1007/s11064-01902908-z

64. Li S, Jiang Z, Chai W, et al (2019) Autophagy activation alleviates nonylphenol-induced apoptosis in cultured cortical neurons. Neurochem Int 122:73-84. https://doi.org/10.1016/j.neuint.2018.11.009

65. Beker M, Dallı T, Elibol B (2018) Thymoquinone Can Improve Neuronal Survival and Promote Neurogenesis in Rat Hippocampal Neurons. Mol Nutr Food Res 62:. https://doi.org/10.1002/mnfr.201700768

66. Kanter M (2008) Nigella sativa and derived thymoquinone prevents hippocampal neurodegeneration after chronic toluene exposure in rats. Neurochem Res 33:579-588. https://doi.org/10.1007/s11064-007-9481-z

67. Escartin C, Galea E, Lakatos A, et al Reactive astrocyte nomenclature, definitions, and future directions | Enhanced Reader. nature.com

68. Hausmann R, Rieß R, Fieguth A, Betz P (2000) Immunohistochemical investigations on the course of astroglial GFAP expression following human brain injury. Int $J$ Legal Med 113:70-75. https://doi.org/10.1007/PL00007711 
69. Jie $Y$, Xuefeng $Y$, Mengxue $Y$, et al (2016) Mechanism of nonylphenol-induced neurotoxicity in F1 rats during sexual maturity. Wien Klin Wochenschr 128:426-434. https://doi.org/10.1007/s00508-0160960-6

70. Maroteaux L, Campanelli JT, Scheller RH (1988) Synuclein: A neuron-specific protein localized to the nucleus and presynaptic nerve terminal. J Neurosci 8:2804-2815.

https://doi.org/10.1523/jneurosci.08-08-02804.1988

71. Davidson WS, Jonas A, Clayton DF, George JM (1998) Stabilization of a-Synuclein secondary structure upon binding to synthetic membranes. J Biol Chem 273:9443-9449.

https://doi.org/10.1074/jbc.273.16.9443

72. Saleh H, Saleh A, Yao H, et al (2015) Mini review: Linkage between a-Synuclein protein and cognition. Transl Neurodegener 4:1-6. https://doi.org/10.1186/s40035-015-0026-0

73. Alhebshi AH, Odawara A, Gotoh M, Suzuki I (2014) Thymoquinone protects cultured hippocampal and human induced pluripotent stem cells-derived neurons against a-synuclein-induced synapse damage. Neurosci Lett 570:126-131. https://doi.org/10.1016/j.neulet.2013.09.049

74. Gómez-Benito M, Granado N, García-Sanz P, et al (2020) Modeling Parkinson's disease with the alpha-synuclein protein. Front Pharmacol 11:356

\section{Tables}

Table 1. List of primary and secondary antibodies

\begin{tabular}{|lllll|}
\hline antibody & Company & Cat \# & Concentration & Host \\
\hline GFAP & Sigma-Aldrich & G3893 & $1 / 200$ & Mice \\
\hline GLAST & Abcam & AB416 & $1 / 200$ & Rabbit \\
S100 $\beta$ & Abcam & AB52642 & $1 / 200$ & Rabbit \\
\hline Anti-rabbit & Invitrogen & A10040 & $1 / 1000$ & Donkey \\
\hline Anti-rabbit & Invitrogen & A11008 & $1 / 1000$ & Goat \\
\hline Anti-mouse & Sigma-Aldrich & AP500F & $1 / 1000$ & Goat \\
\hline
\end{tabular}

Table2. Primer sequences 


\begin{tabular}{|lll|}
\hline $\begin{array}{l}\text { Genes symbols } \\
\text { GFAP Forward }\end{array}$ & Accession ID & Sequence (5'-3') \\
GFAP Reverse & NM-01700.9F & GGTCATTAAGGAGTCGAAGCAGGAG \\
a-Syn forward & NM-019169.3F & ACCAAGACTATGAGCCTGAAGCC \\
a-Syn reverse & NM-019169.3R & GGAACTGAGCACTTGTACGCC \\
\hline GAPDH forward & NM-017008.4F & ACCAAGACTATGAGCCTGAAGCC \\
& & \\
GAPDH reverse & NM-017008.4.R & GGAACTGAGCACTTGTACGCC \\
\hline
\end{tabular}

Figures 

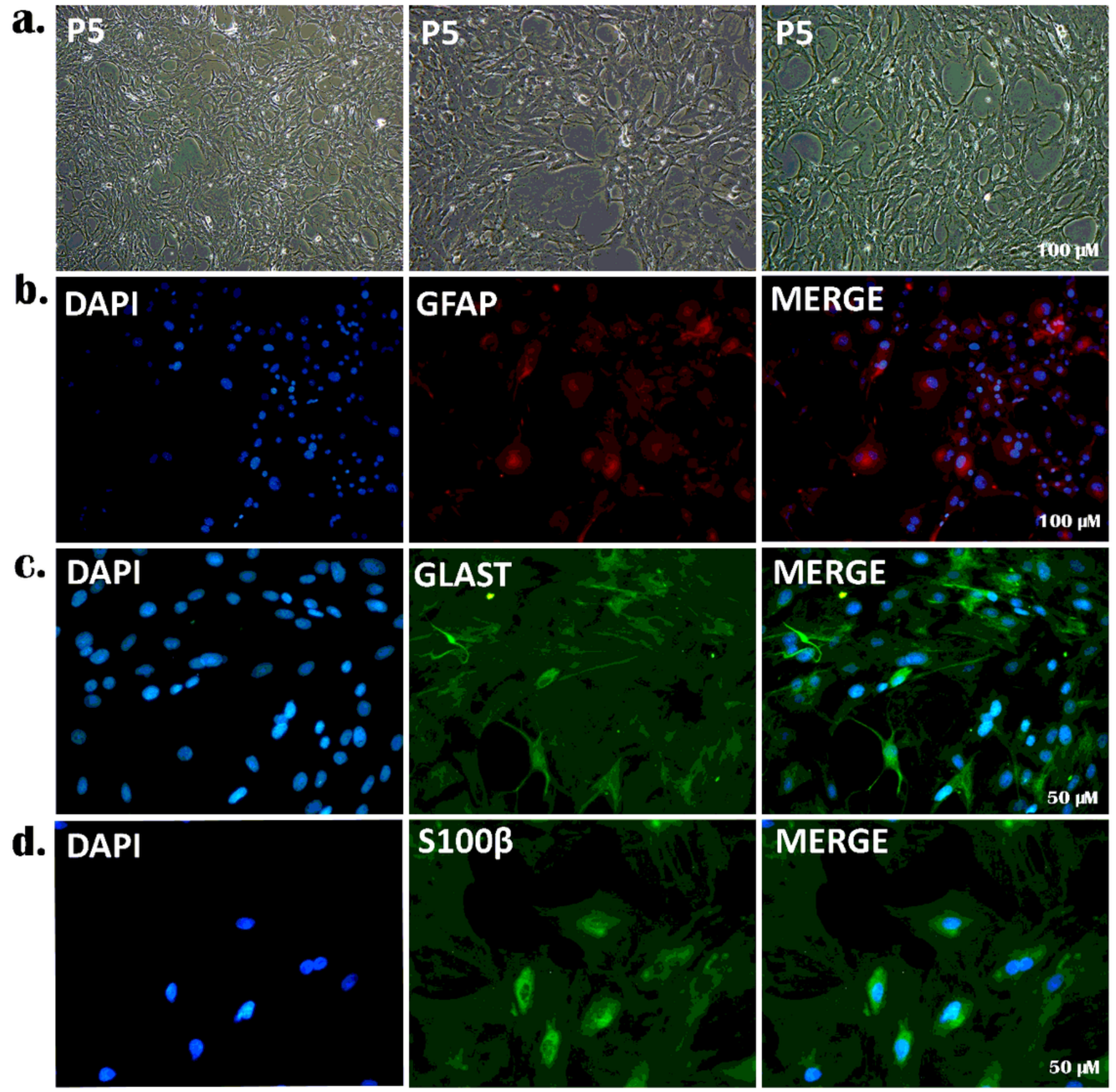

\section{Figure 1}

Characterization of isolated astrocyte from mice brain. a Phase contrast microscopy reveals that primary astrocytes have a polygonal to fusiform and flat shape under normal condition during 5 passages. Fig (1, b-d). Immunofluorescence of GFAP (b), GLAST (c) and S100 $\beta$ (d) as astrocyte markers in the primary culture after passages 5 were shows our culture is purely astrocytes. 


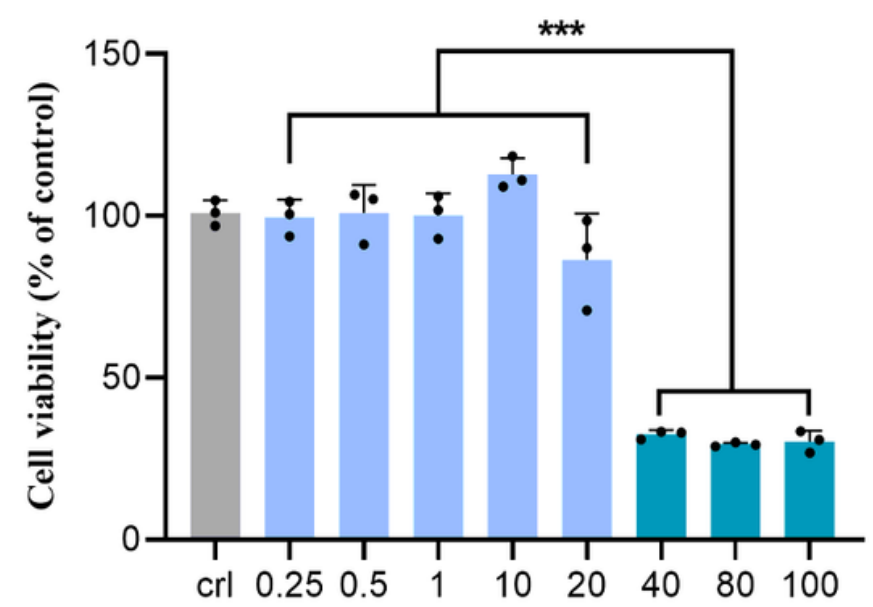

a.
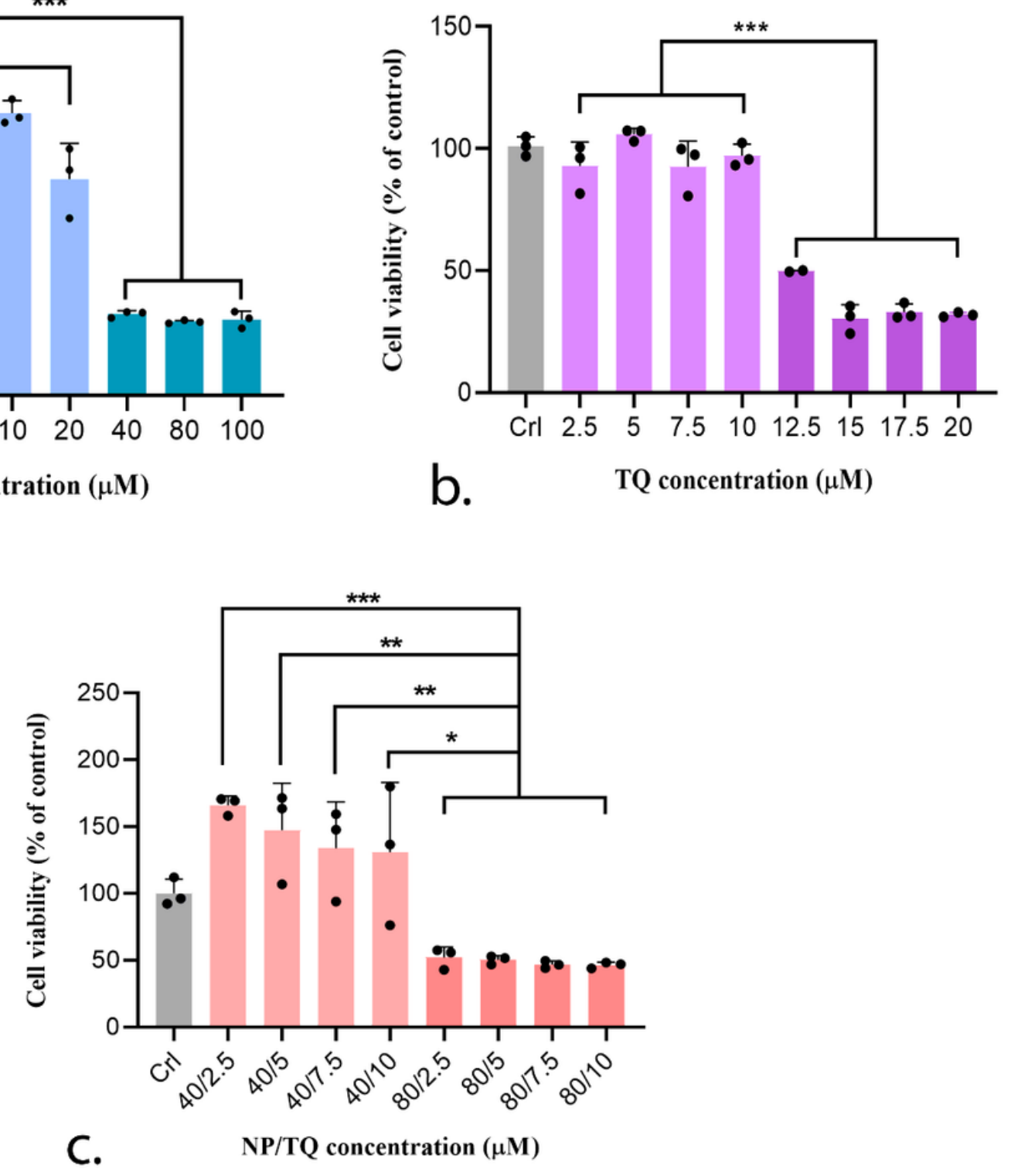

Figure 2

The effect of Nonylphenol (NP) and Thymoquinone (TQ) on cell survival an Astrocyte treated with graded concentrations of NP and tested after $24 \mathrm{~h}$ using the MTS assay. Cell viability of NP exposed cells was noticeably decreased in the concentrations of 40,80 , and $100 \mu \mathrm{M}$ compared to the control group (all, $\mathrm{p}<0.0001)$. Data is from three independent experiments. Bars indicate mean $\pm \mathrm{SEM}$. one-way ANOVA with post-hoc Tukey test, ( $* \star * p<0.001)$. (b) Cells were treated with graded concentrations of TQ and tested after $24 \mathrm{~h}$ using the MTS assay. TQ significantly reduced primary astrocyte viability at 12.5, 15, 17.5 and $20 \mu \mathrm{M}$ (all, $p<0.001)$. Bars indicate mean \pm SEM. one-way ANOVA with post-hoc Tukey test, $\left({ }^{*} p<0.05\right.$ ** $p<0.01 * * \star p<0.001$ ). (c) Cells were treated with combine concentrations of NP and TQ and tested after 24 h using the MTS assay. MTS assay for astrocyte cells after exposure to the NP plus TQ showed an 
increase in cells survival at dose of $40 / 2.5 \mu \mathrm{M}$ in compared to control and other groups. Data gathered from three independent experiments. Bars indicate mean \pm SEM. one-way ANOVA with post-hoc Tukey test, $\left({ }^{*} p<0.05 * * p<0.01 * \star * p<0.001\right)$.

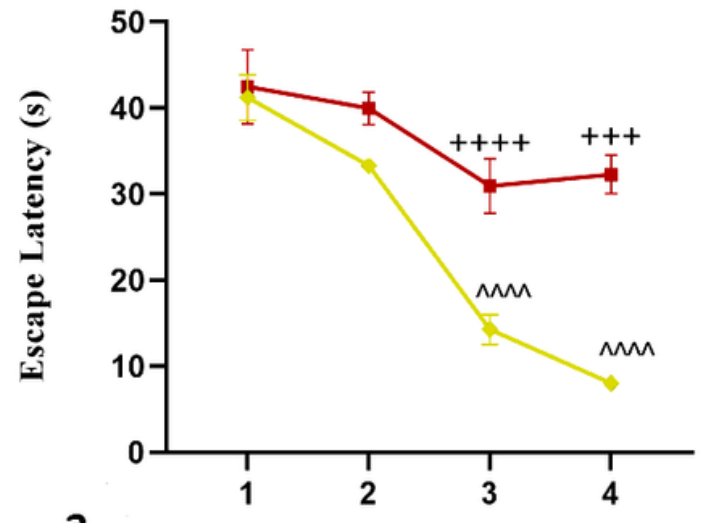

a.

Days

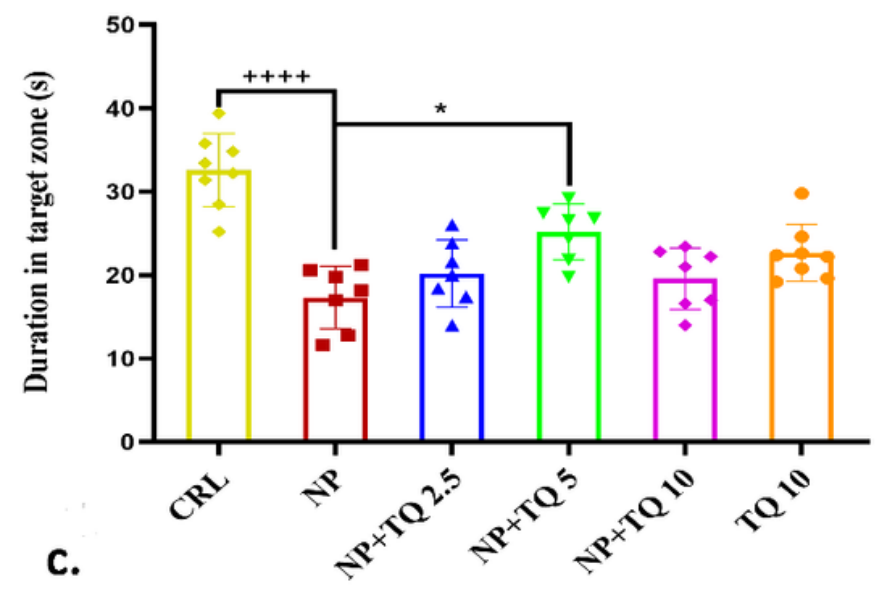

groups

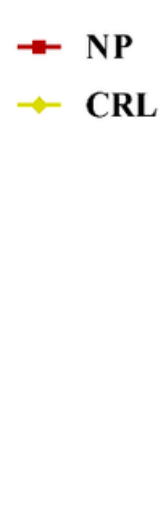

b.

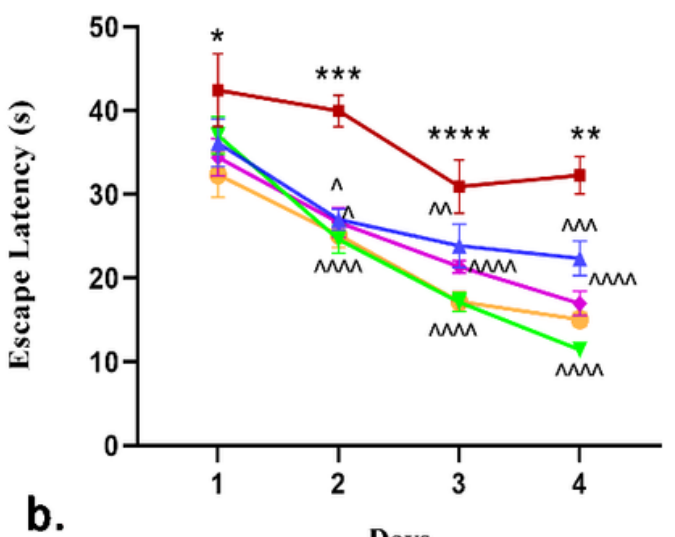

Days

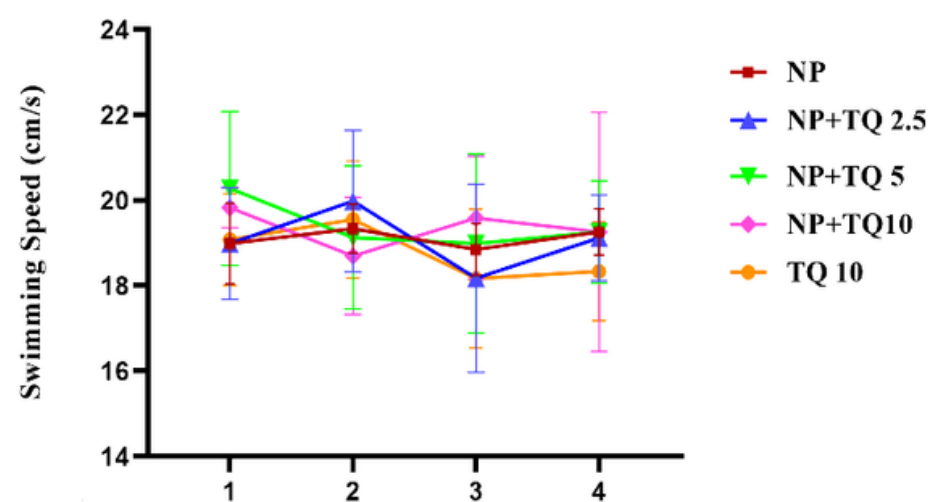

d.

Days

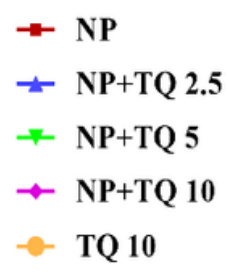

\section{Figure 3}

TQ improves NP-induced spatial learning and memory deficit. (a-b): comparison of escape latency, (d): swimming velocity in all treatment groups. The escape latency in Nonylphenol (NP) group was considerably more than that control (CRL) group on days 3 and 4 of training $(++++p<0.0001$, $+++p<0.001)$. In the CRL group, the escape latency index significantly decreased on days 3 and 4 compared to the first day of examination ( ${ }^{\wedge \wedge \wedge} p<0.0001$, Fig 3-a). Moreover, the escape latency in TQ treated groups at all doses was significantly decreased at day 2,3 and 4 of training trails compared to the first day. On day 1 , the escape latency in NP+TQ $(10 \mathrm{mg} / \mathrm{kg})$ treated group was significantly decreased compared to the NP group ( $\left.{ }^{*} p=0.04\right)$. On day 2 , TQ decreased the escape latency at all doses compared to NP group. On day 3 , it has been observed that escape latency index in NP+TQ $(2.5 \mathrm{mg} / \mathrm{kg}$, $\star \star \star \star \mathrm{p}=0.002)$ and NP+TQ $\left(5 \mathrm{mg} / \mathrm{kg},{ }^{* \star *} \mathrm{p}<0.0001\right)$ was noticeably shorter than that compared to the NP group. On day 4, the escape latency in TQ treated groups at all doses was significantly lesser than that compared to NP group (3-b). (c): assessment of time duration spent in the target zone, NP-treated animals spent less time 
in target quadrant $(\mathrm{Q} 4)$ than the $\mathrm{CRL}$ group $(++++p<0.0001)$. Moreover, $\mathrm{TQ}$ treatment only at the dose of $5 \mathrm{mg} / \mathrm{kg}$ significantly enhanced the time spent in the target quadrant compared to the NP group $(* p<0.05$, Fig 3-c). $\left({ }^{\wedge}\right)$ sign indicates significant difference in NP group compared to CRL group and $\left({ }^{*}\right)$ sign indicates significant difference in NP group compared to TQ treatment groups.
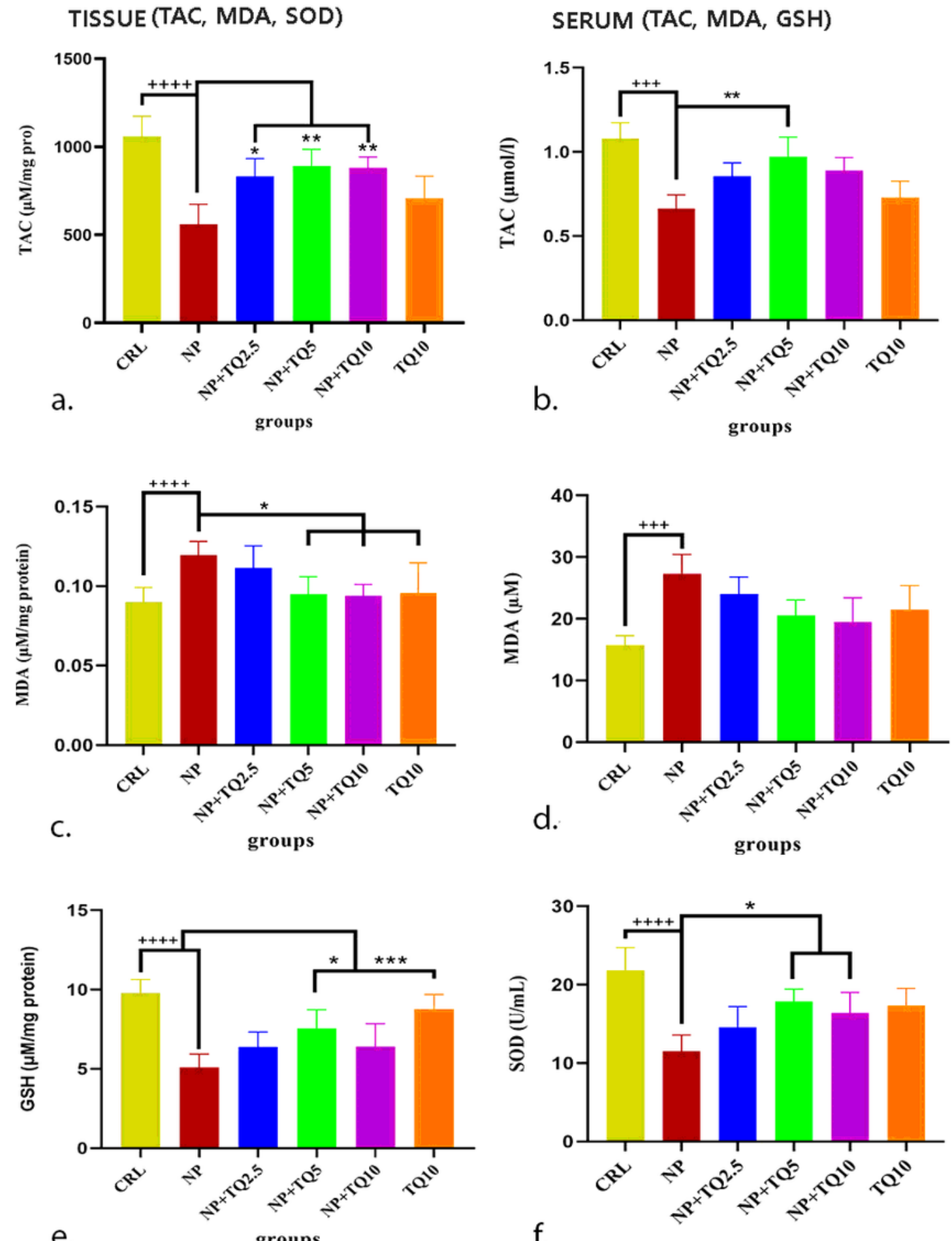

e.

groups

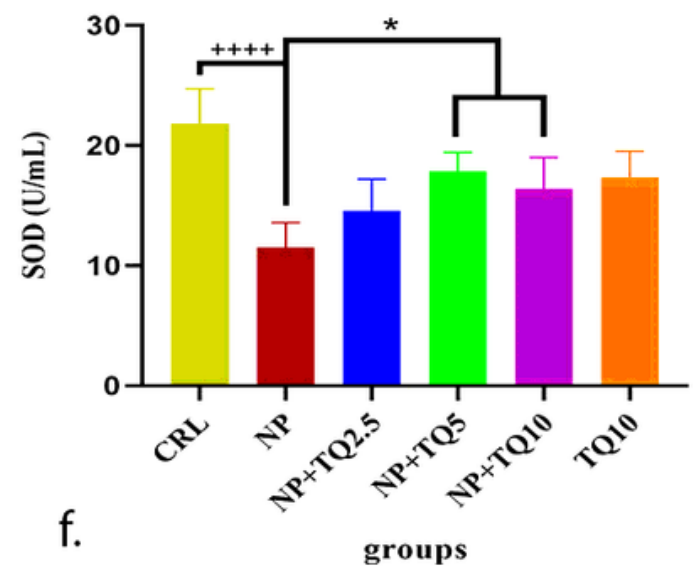

Figure 4 
Thymoquinone (TQ) treatment enhanced antioxidant capacity against NP-induced neurotoxicity. Rat brain were used at the end of the experiment to assess the measurement of Total TAC (a-b), MDA (c-d), GSH (e), and SOD (f). The results showed that NP-induced group significantly increased the brain $(++++p<0.0001)$ and serum $(+++p<0.001)$ levels of TAC $(a-b)$ compared to the control $(C R L)$ group. The brain TAC level significantly increased in TQ treatment at doses of $(2.5,5,10 \mathrm{mg} / \mathrm{kg})$ respectively $\left({ }^{\star} p<0.05,{ }^{*} p<0.01,{ }^{* \star} p<0.01\right)$. On serum level, only TQ at a dose of $(5 \mathrm{mg} / \mathrm{kg})$ increased TQ level significantly $(* \star p<0.01)$. Results of MDA assay indicated that both tissue $(++++p<0.0001)$ and serum $(+++p<0.001)$ levels of the MDA increase in the NP-treated group compared to CRL group. Moreover, TQ in all doses except $(2.5 \mathrm{mg} / \mathrm{kg})$ modulated brain MDA level $\left({ }^{*} p<0.05, \mathrm{c}-\mathrm{d}\right)$. Furthermore, the results indicated that the brain GSH $(++++p<0.0001)$ and serum SOD $(++++p<0.0001)$ levels in NP group were lesser than that in CRL group (e-f). Moreover, it has been observed a significant increase on GSH level in NP+TQ $\left(5 \mathrm{mg} / \mathrm{kg},{ }^{*} \mathrm{p}<0.05\right)$ and TQ $\left(10 \mathrm{mg} / \mathrm{kg},{ }^{* \star *} \mathrm{p}<0.001\right)$ groups compared to NP group (e). SOD assay showed that TQ at doses of ( 5 and $10 \mathrm{mg} / \mathrm{kg}$ ) increased serum SOD level $\left({ }^{*} \mathrm{p}<0.05, \mathrm{f}\right)$.

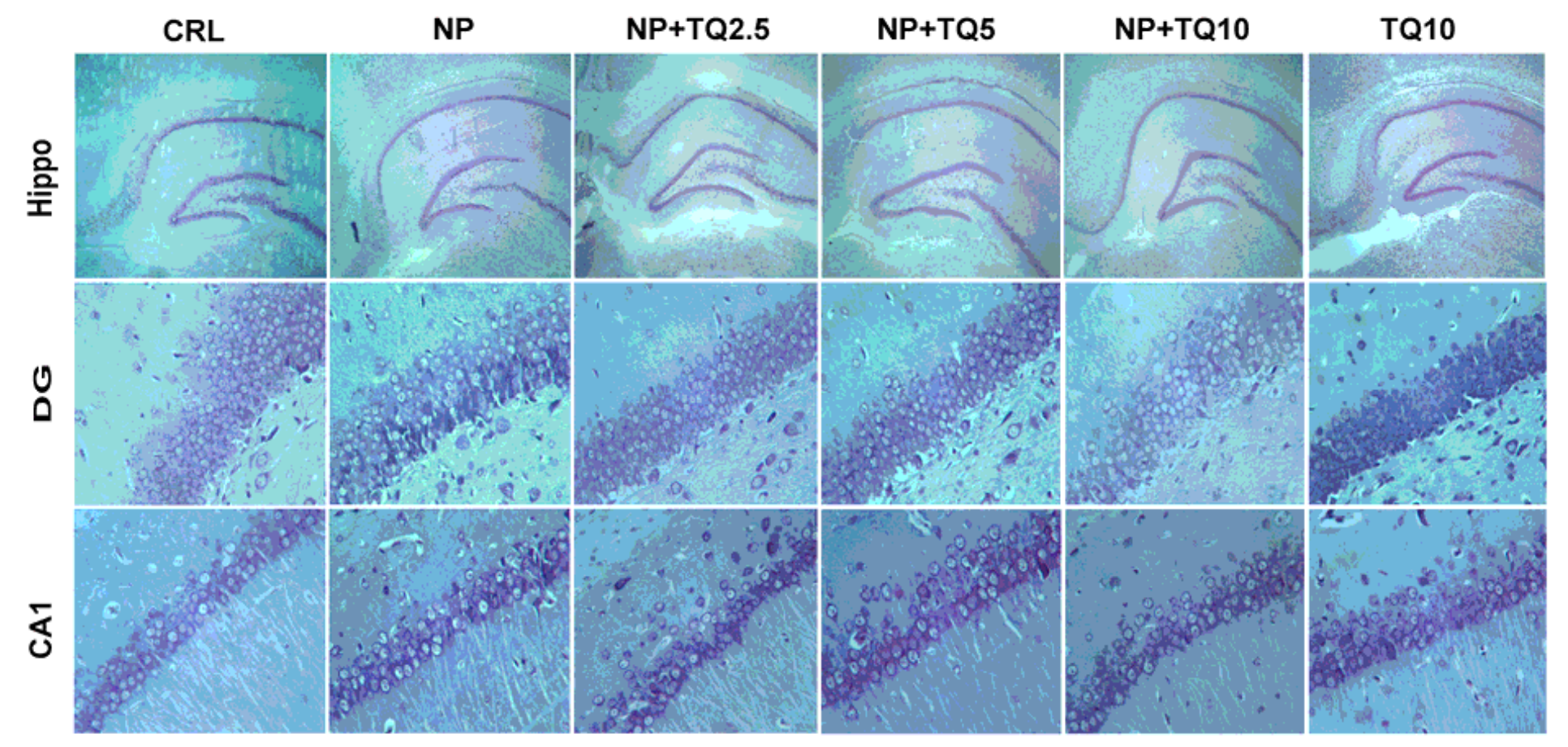

Figure 5

Effect of Thymoquinone (TQ) on histopathological changes induced by Nonylphenol (NP) in rat models. Histopathological changes were evaluated using Nissl staining. Representative images for control (CRL), NP, NP+TQ2.5, NP+TQ5, NP+TQ10, and TQ10 are provided (magnification: $\times 400, \times 40$ ). 


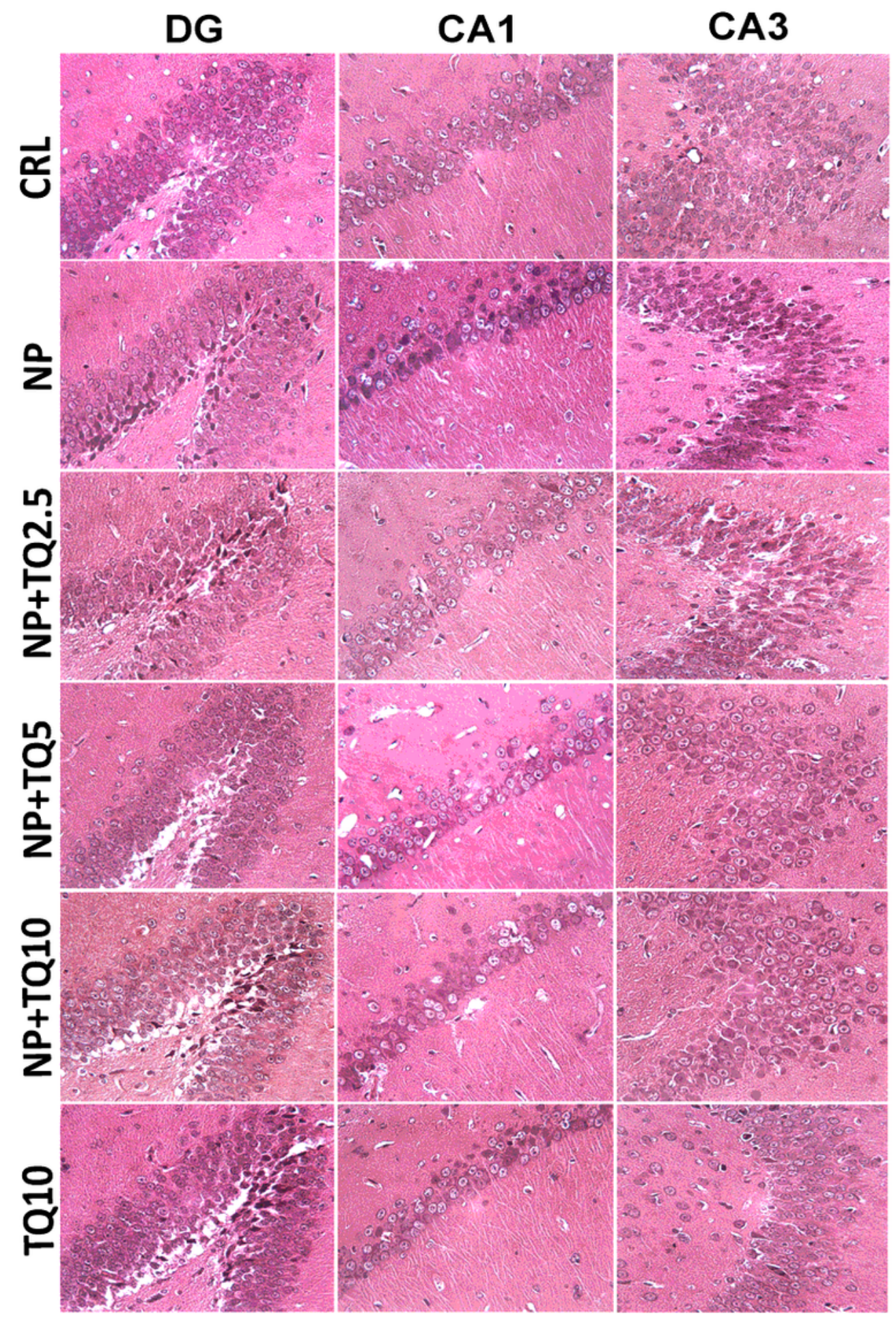

Figure 6

Effect of Thymoquinone (TQ) on histopathological changes induced by Nonylphenol (NP) in rat models. Histopathological changes were evaluated using H\&E staining. Representative images for control (CRL), NP, NP+TQ2.5, NP+TQ5, NP+TQ10, and TQ10 are provided (magnification: $\times 400$ ). 

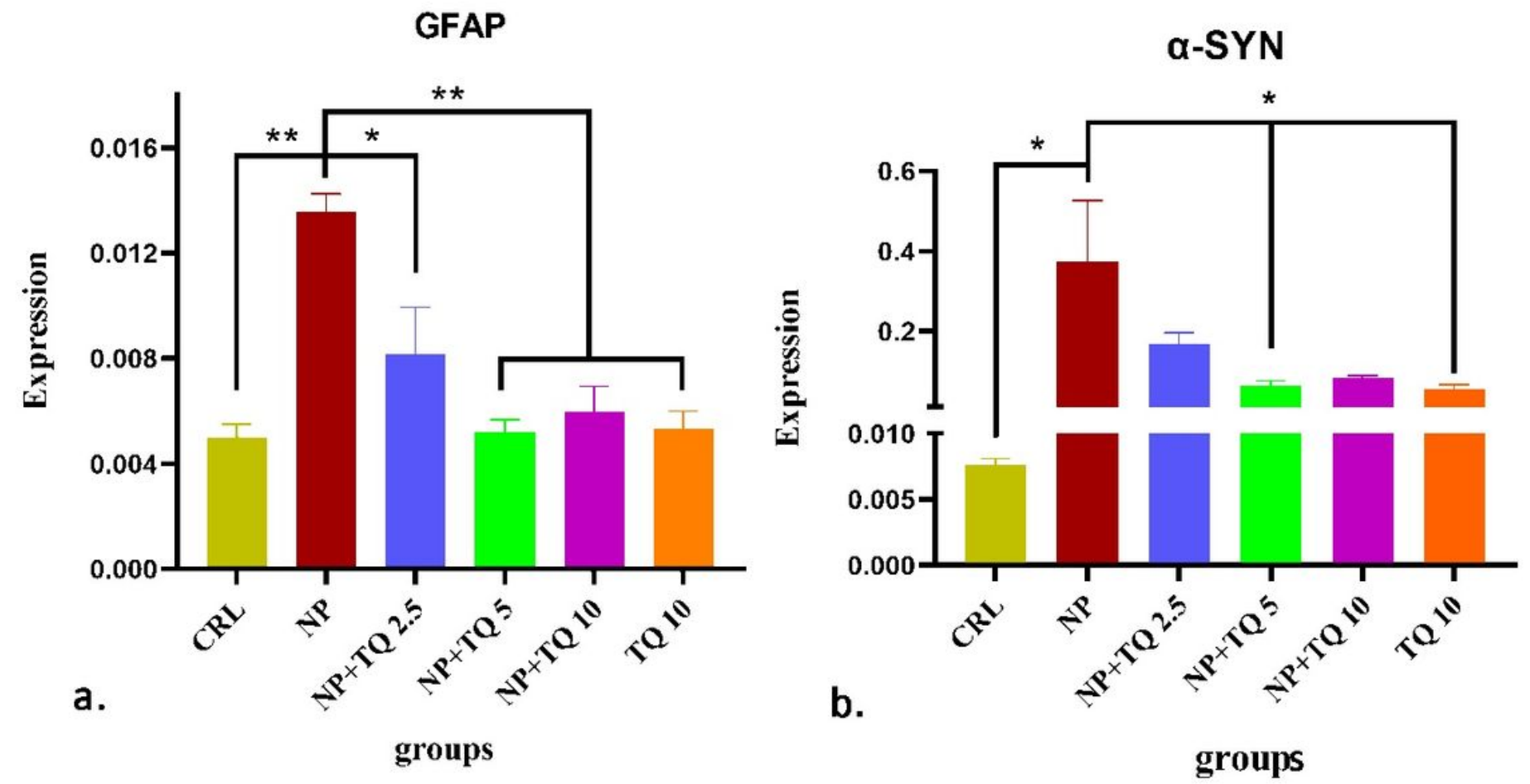

Figure 7

TQ treatment moderated the expression of genes by its neuroprotective properties. The results showed that Nonylphenol (NP)-induced neurotoxicity significantly upregulated the expression level of GFAP compared to the control (CRL) group ( $\left.{ }^{* *} p<0.01, a-b\right)$. Our molecular results showed that in all Thymoquinone (TQ)-treated groups $(2.5,5,10 \mathrm{mg} / \mathrm{kg})$, there was a significant reduction in GFAP gene expression ( ${ }^{*} p<0.05,{ }^{*} p<0.01$, and ${ }^{* *} p<0.01$ respectively, Fig $\left.7-a\right)$. Moreover, expression of $a-S y n$ was increased in NP group compared to CRL group $\left({ }^{\star} p<0.05\right.$, Fig7-b). Furthermore, in TQ treatment groups at doses of 5 and $10 \mathrm{mg} / \mathrm{kg}$, a-Syn expression downregulated compared to NP group ( ${ }^{*} p<0.05$, Fig 7-b). Oneway ANOVA (Tukey's post-test) was used to perform statistical analysis.

\section{Supplementary Files}

This is a list of supplementary files associated with this preprint. Click to download.

- GraphicalAbstract.tif 